\title{
Coupling Vibration Analysis of Turbine Shared Support Rotor- Bearing System with Squeeze Film Dampers
}

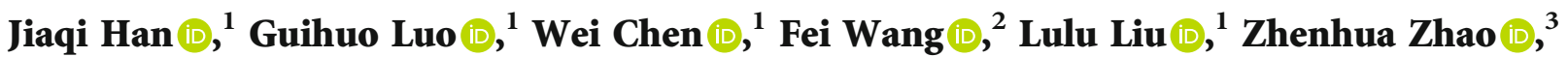 \\ and Gang Luo $\mathbb{i D}^{3}$ \\ ${ }^{1}$ Key Laboratory of Aero-Engine Thermal Environment and Structure, Ministry of Industry and Information Technology, College of \\ Energy and Power Engineering, Nanjing University of Aeronautics and Astronautics, Nanjing 210016, China \\ ${ }^{2}$ School of Aircraft Engineering, Nanchang Hangkong University, Nanchang 330063, China \\ ${ }^{3}$ State Key Laboratory of Mechanics and Control of Mechanical Structures, Nanjing University of Aeronautics and Astronautics, \\ Nanjing 210016, China
}

Correspondence should be addressed to Wei Chen; chenwei@nuaa.edu.cn

Received 15 October 2021; Revised 19 December 2021; Accepted 12 January 2022; Published 5 February 2022

Academic Editor: Guillermo Valencia-Palomo

Copyright (C) 2022 Jiaqi Han et al. This is an open access article distributed under the Creative Commons Attribution License, which permits unrestricted use, distribution, and reproduction in any medium, provided the original work is properly cited.

\begin{abstract}
The turbine shared support structure is used widely in aeroengines, but theoretical and experimental research on a rotor-bearing system containing a shared turbine support structure is lacking. This paper reports research into the coupling vibration response of a squeeze-film-damper rotor-bearing system that has two spools with different rotation speeds and is supported by a turbine shared support structure. The problem is addressed by means of experimental tests and the finite-element method. Based on the features of a turboshaft engine with a turbine shared support structure, a rotor-bearing test system with a shared support structure and squeeze film damper is designed, and a finite-element model of the test system is built based on Timoshenko beam elements. The experimental and simulation results indicate that the unbalanced response of the rotor-bearing system with a shared support structure may involve either the sum or difference of the fundamental frequencies of the rotors of the gas generator and power turbine. The simulations show that the unbalance of the power turbine rotor, the radial and bending stiffnesses of the shared support structure, and the radial clearances of squeeze film dampers at the shared support structure of the rotor-bearing system all affect the coupling response. The amplitude of the coupling response can be suppressed effectively by (i) selecting reasonable parameter values for the turbine shared support structure and (ii) exerting strict control over the spool unbalance.
\end{abstract}

\section{Introduction}

The core components of an aeroengine are its rotor-bearing systems, and the vibration characteristics of the latter determine directly whether the engine can work in harsh environments with high temperatures, pressures, speeds, and high loads, meanwhile, the vibration condition which has a critical influence on the overall performance of the engine. With improvements in aeroengine performance and increased reliability requirements, modern aeroengine rotor-bearing systems are mostly dual-rotor ones. The support scheme at the turbine involves rotor-bearing systems with either intermediate bearings or a turbine shared support structure
(SSS), and the different supporting structures result in different coupling vibrations between the rotor-bearing systems.

Different from the intermediate bearing support scheme, the SSS scheme avoids the direct connection between the two rotors and can effectively reduce the vibration transmission between the rotors, the turbine SSS is effective in large turbofan engines at coordinating the larger transition ducts between the high-pressure and low-pressure turbines, such as in the GE90 and CF6-50 aeroengines, and it has a better impact on the clearances of high-pressure-ratio components in the hot section of mid-size turbofan engines compared to when intermediate bearing support is used $[1,2]$. The SSS is also effective at controlling the power turbine (PT) 


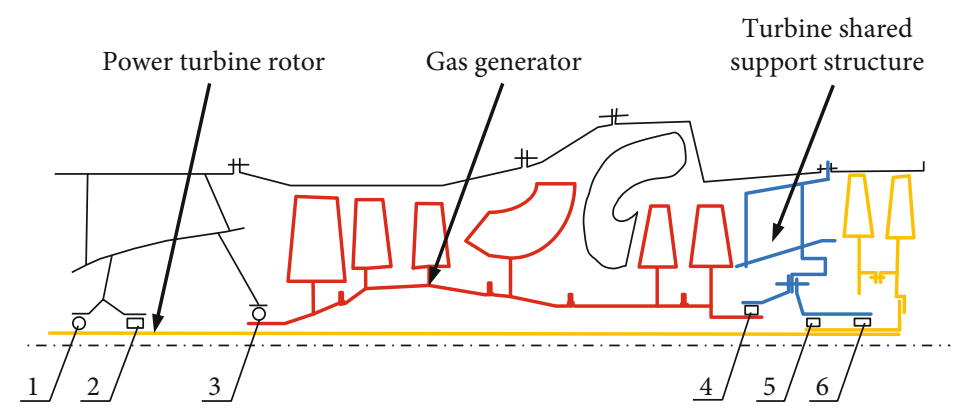

Figure 1: Structural diagram of turboshaft engine.

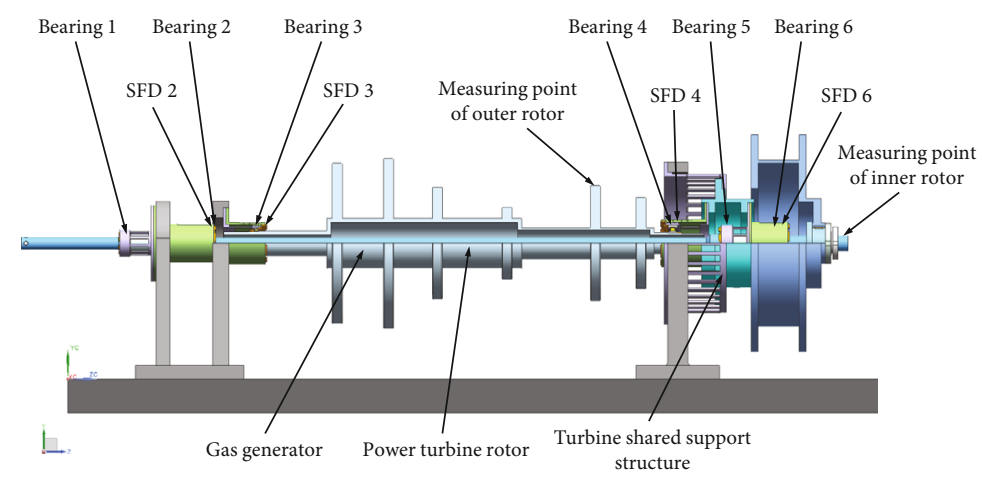

(a)

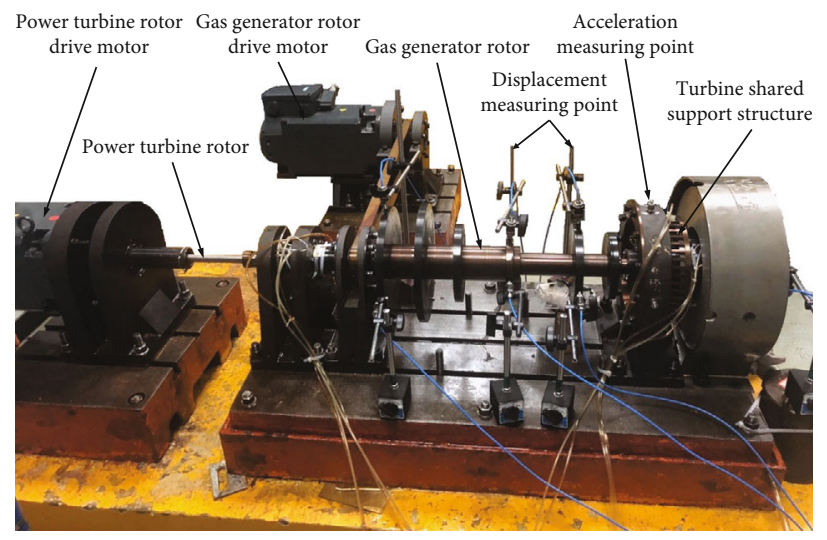

(b)

Figure 2: Rotor-bearing test system: (a) schematic; (b) photograph.

tip clearance in turboshaft engines and improving the turbine efficiency and maintenance performance. The PT can be replaced without exposing the rear bearing cavity, such as in the MTR390 aeroengine.

In summary, the turbine SSS is used widely in large, medium, and small engines. However, it contains nonlinear components in the form of squeeze film dampers (SFDs), and it carries two spools that rotate simultaneously with different speeds. Therefore, the nonlinear characteristics of the oil films in the SFDs and the mutual vibration between the two spools have adverse effects on the dynamic responses of the rotor-bearing systems in aeroengines.

In the past few decades, much work has been done on coupling vibration analysis of rotor-bearing and whole-

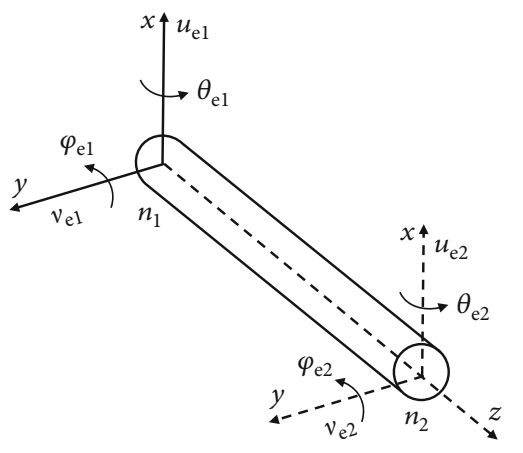

FIgURE 3: Schematic diagram of beam element. 


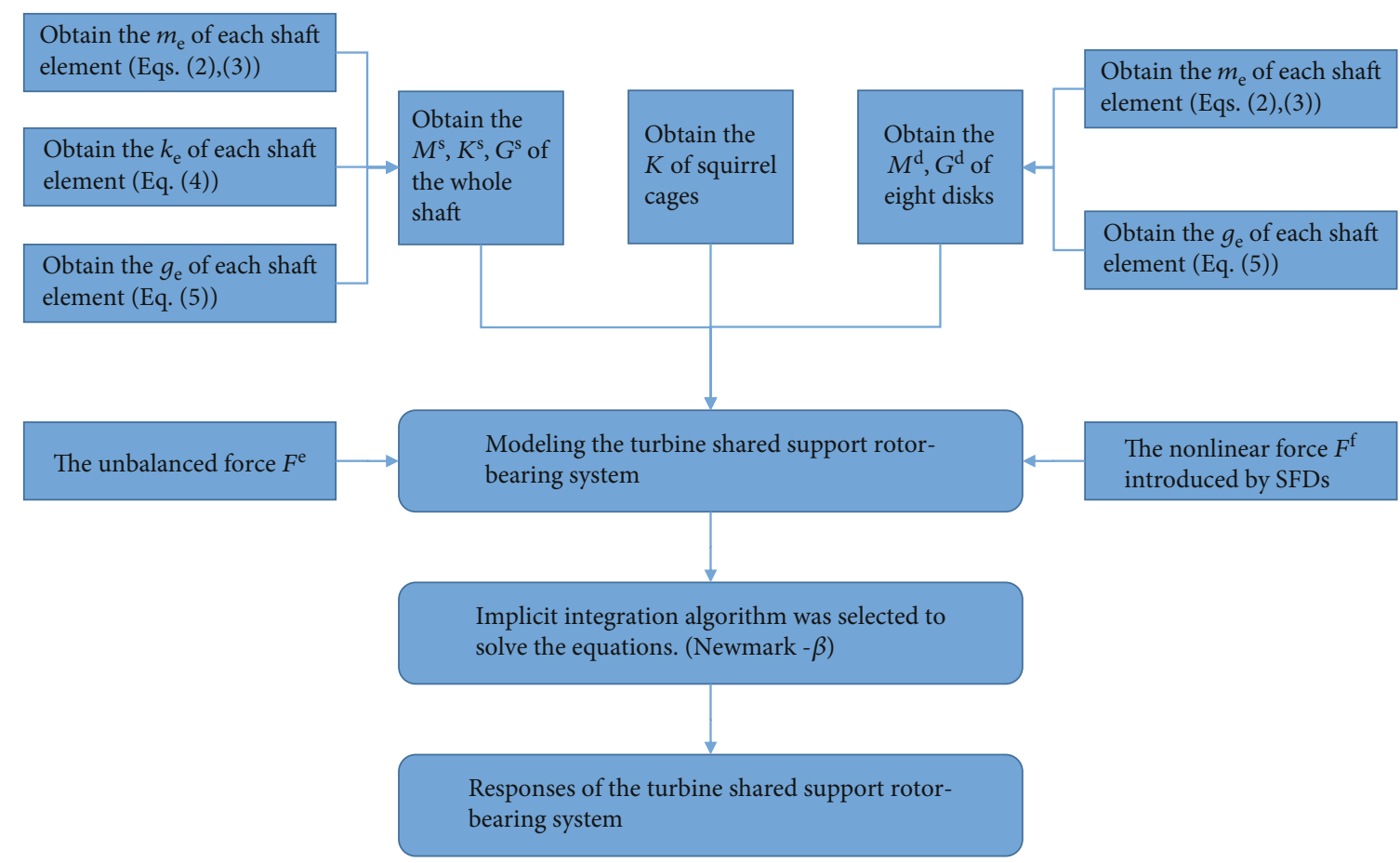

FIGURE 4: Flow chart of rotor-bearing system modeling and solution.

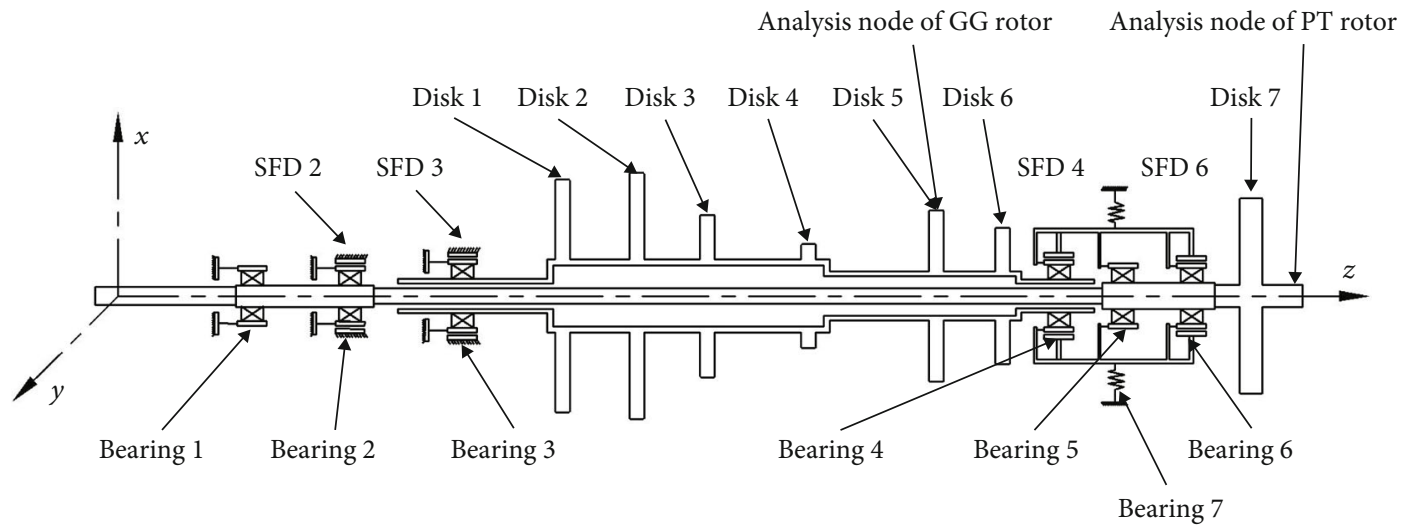

FIGURE 5: Simplified analysis model.

engine systems in aeroengines, resulting in many achievements. However, that literature concerns mainly the coupling vibrations of rotor-bearing and whole-engine systems containing intermediate bearings, with the main modeling approaches involving Newton's second law, the Lagrange equations, and the finite-element (FE) method. Lu et al. [3, 4], Thiery and Aidanpäaä [5], and Yang et al. [6] used Newton's second law to establish an analysis model of a rotorbearing system containing nonlinear components. Gao et al. [7, 8] and Hou et al. [9] used the Lagrange equations to establish a dynamic model of a dual-rotor-bearing system with nonlinear elements and studied its response. Lu et al. [10], Wang et al. [11], Chen [12], Yu et al. [13], and Yang et al. [14] established a dynamic model of dual-rotorbearing and whole-engine systems using the FE method.

As suggested by the aforementioned studies, Newton's second law and the Lagrange equations tend to be used to establish dynamic models of rotor-bearing systems with simple structures and relatively few degrees of freedom, whereas the FE method tends to be used to establish dynamic models of complex rotor-bearing and wholeengine systems. Therefore, for the present study, we chose the FE method based on Timoshenko beam elements as the modeling method to establish the dynamic model of the test system with a turbine SSS.

Using beam elements to simulate the rotating shaft when establishing an analysis model of a rotor-bearing system of an aeroengine dates back to the 1970s [15-17]; the shaft was simulated as a Timoshenko beam, the dynamic model of the dual-rotor-bearing system containing intermediate bearings was built by component mode synthesis, and the influence of modal truncation on the calculation results was studied. Subsequently, Nelson et al. [18] established a dynamic model of a rotor-bearing system containing SFDs 
TABle 1: Parameters of disks.

\begin{tabular}{|c|c|c|c|c|c|c|c|}
\hline & Disk number & Location $(\mathrm{mm})$ & Node number & Mass $(\mathrm{kg})$ & $\mathrm{IP}\left(\mathrm{kg} \cdot \mathrm{m}^{2}\right)$ & Unbalance $(\mathrm{g} \cdot \mathrm{cm})$ & Initial phase \\
\hline \multirow{6}{*}{ Gas-generator rotor } & 1 & 467 & 132 & 4.66 & 0.03589 & 2 & $0^{\circ}$ \\
\hline & 2 & 543 & 139 & 5.26 & 0.04488 & 2 & $135^{\circ}$ \\
\hline & 3 & 615 & 146 & 2.01 & 0.00825 & 1 & $90^{\circ}$ \\
\hline & 4 & 718.5 & 156 & 0.53 & 0.00111 & 0 & $0^{\circ}$ \\
\hline & 5 & 849 & 169 & 2.49 & 0.009724 & 2 & $45^{\circ}$ \\
\hline & 6 & 916.5 & 176 & 1.48 & 0.003764 & 2 & $0^{\circ}$ \\
\hline Power-turbine rotor & 7 & 1164 & 116 & 5.16 & 0.07261 & 5 & $0^{\circ}$ \\
\hline
\end{tabular}

TABLE 2: Stiffness of squirrel cages.

\begin{tabular}{lcccc}
\hline $\begin{array}{l}\text { Bearing } \\
\text { number }\end{array}$ & $\begin{array}{c}\text { Location } \\
(\mathrm{mm})\end{array}$ & $\begin{array}{c}\text { Node } \\
\text { number }\end{array}$ & $k_{x x}(\mathrm{~N} / \mathrm{m})$ & $k_{x z}(\mathrm{~N} \cdot \mathrm{m} / \mathrm{rad})$ \\
\hline 1 & 155 & 15 & $3.77 e 6$ & 0 \\
2 & 265 & 26 & $2.35 e 5$ & 0 \\
3 & 348 & 120 & $1.13 e 6$ & 0 \\
4 & 964 & 180 & $7.1 e 5$ & 0 \\
5 & 1045 & 104 & $4.13 e 6$ & 0 \\
6 & 1120 & 112 & $2.3 e 5$ & 0 \\
7 & 1036.5 & 195 & $5 e 7$ & $1 e 7$ \\
\hline
\end{tabular}

TABLE 3: Parameters of shafts.

\begin{tabular}{lccccc}
\hline & $\begin{array}{c}\text { Section } \\
\text { number }\end{array}$ & $\begin{array}{c}\text { Start } \\
\text { point } \\
(\mathrm{mm})\end{array}$ & $\begin{array}{c}\text { End } \\
\text { point } \\
(\mathrm{mm})\end{array}$ & $\begin{array}{c}\text { Outer } \\
\text { diameter } \\
(\mathrm{mm})\end{array}$ & $\begin{array}{c}\text { Inner } \\
\text { diameter } \\
(\mathrm{mm})\end{array}$ \\
\hline $\begin{array}{l}\text { Gas-generator } \\
\text { rotor }\end{array}$ & 2 & 299 & 451.5 & 26 & 37 \\
& 3 & 740 & 936 & 40 & 46 \\
& 4 & 936 & 1010 & 26 & 37 \\
Power-turbine & 7 & 287.17 & 1013.63 & 0 & 16 \\
rotor & 5 & 0 & 136 & 0 & 18.4 \\
& 8 & 1013.63 & 1133.93 & 0 & 25 \\
Shared & 9 & 1133.93 & 1223.63 & 0 & 23 \\
support & 10 & 947.5 & 1134.5 & 120.5 & 125.5 \\
structure & & & & & \\
\hline
\end{tabular}

and intermediate bearings and calculated the unbalanced response, the transient response of the blade loss, and the transient response after rotor and stator friction; the calculation results were validated through cross-comparison with other independent documents. Chiang et al. $[19,20]$ established a dynamic model of a rotor-bearing system with intermediate bearings; they calculated the critical speeds and vibration modes of the system and verified them with a single-rotor test system, but the established analysis model did not consider nonlinear factors. Wang et al. [21] established a rotor-bearing model that considered intermediate bearings and nonlinear SFD characteristics, and they carried out a rotor-bearing test to verify their proposed model-
Table 4: Parameters of SFDs.

\begin{tabular}{lccccc}
\hline & $\begin{array}{c}\text { Support } \\
\text { number }\end{array}$ & $\begin{array}{c}L \\
(\mathrm{~mm})\end{array}$ & $\begin{array}{c}R \\
(\mathrm{~mm})\end{array}$ & $\begin{array}{c}c \\
(\mathrm{~mm})\end{array}$ & $\begin{array}{c}\text { Dynamic } \\
\text { viscosity } \\
\left(10^{-2} \mathrm{~Pa} \cdot \mathrm{s}\right)\end{array}$ \\
\hline Power-turbine & 2 & 19 & 23 & 0.05 & \\
rotor & 6 & 15.5 & 26.5 & 0.05 & 1.0752 \\
Gas-generator & 3 & 9.5 & 25.5 & 0.05 & \\
rotor & 4 & 17 & 26.5 & 0.05 & \\
\hline
\end{tabular}

TABle 5: Natural frequency comparison $(\omega=0 \mathrm{rpm})$.

\begin{tabular}{|c|c|c|c|c|c|}
\hline & \multirow[t]{2}{*}{ Order } & \multicolumn{3}{|c|}{ Natural frequencies $(\mathrm{Hz})$} & \multirow[t]{2}{*}{$\begin{array}{c}\text { Error } \\
(\%)\end{array}$} \\
\hline & & $\begin{array}{c}\text { The } \\
\text { developed } \\
\text { model }\end{array}$ & $\begin{array}{c}\text { ANSYS } \\
\text { solid } \\
185 \\
\text { model }\end{array}$ & Experiment & \\
\hline \multirow{3}{*}{$\begin{array}{l}\text { Gas-generator } \\
\text { rotor }\end{array}$} & $1 \mathrm{st}$ & 44.47 & 44.36 & 45.83 & 3 \\
\hline & 2nd & 82.97 & 83.04 & 88.34 & 6.1 \\
\hline & $3 \mathrm{rd}$ & 388.69 & 388.97 & 396.02 & 1.9 \\
\hline \multirow{3}{*}{$\begin{array}{l}\text { Power-turbine } \\
\text { rotor }\end{array}$} & $1 \mathrm{st}$ & 26.72 & 26.77 & 27.03 & 1.1 \\
\hline & 2nd & 75.56 & 75.8 & 78.44 & 3.7 \\
\hline & $3 \mathrm{rd}$ & 164.18 & 164.87 & 170.87 & 3.9 \\
\hline
\end{tabular}

ing and analysis methods; their research results indicated that it is feasible to build a complex dual-rotor-bearing system with SFDs and bearings using Timoshenko beam elements. The FE modeling method using Timoshenko beam elements has now developed into an effective method for establishing dynamic models of complex rotor-bearing and whole-engine systems in aeroengines with nonlinear characteristics.

Meanwhile, SFDs are used extensively for vibration suppression in aeroengines [22-25]. However, the severe nonlinear characteristics of the oil-film force in an SFD may result in a dramatic change in the rotor response; more seriously, they may cause instability and damage to the rotor system [26-28]. Many scholars remain concerned about SFD-rotor coupling vibrations. Inayat-Hussain et al. [29] used numerical simulation to investigate the unbalanced response of a single-rotor system containing SFDs without centering springs; with changing shaft unbalance, the response of the rotor system experienced a series of period-doubling 


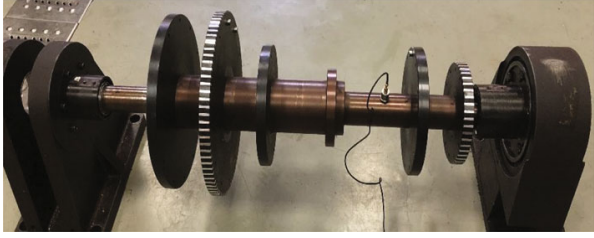

(a)

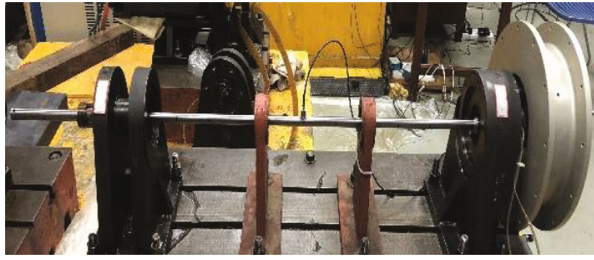

(b)

FiguRE 6: Natural frequency tester: (a) gas-generator rotor tester; (b) power-turbine rotor tester.

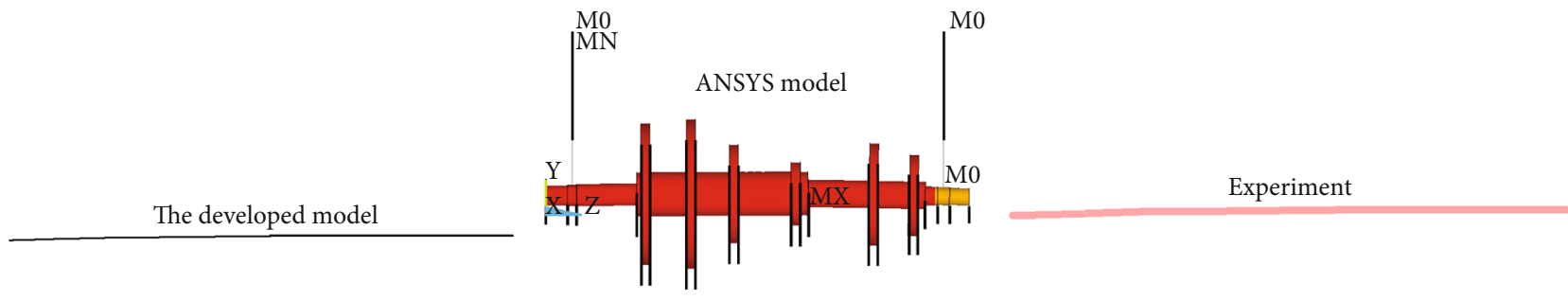

(a)

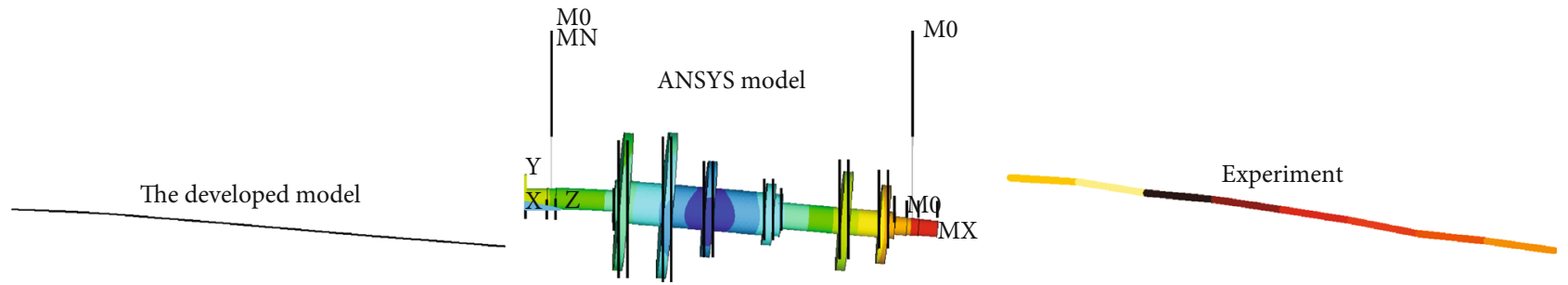

(b)

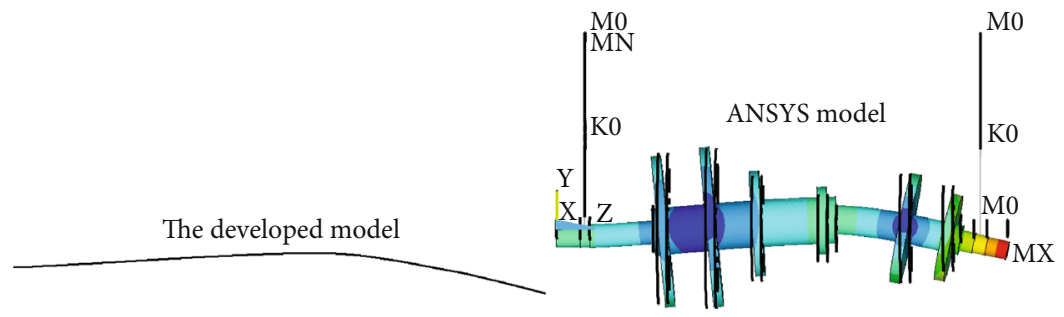

(c)

FIGURE 7: First three model shape of gas-generator rotor: (a) 1st; (b) 2nd; (c) 3rd.

bifurcations that caused the system to enter a state of chaotic motion after a period of time, which introduced cyclic stresses and may have rapidly reduced the fatigue limit of the shaft. Qin et al. [30] suggested that the support stiffness has considerable influence on the SFDs; excessive support stiffness causes oil whirl and leads to SFD failure. Chen et al. [31] studied the coupling relationship between rigid-body translation and precession of SFD-unsymmetrical rotor-bearing systems; the results showed that the bifurcation phenomena of asymmetric and symmetric systems are similar, but for asymmetric systems, the stiffness ratio of the left and right supports may destroy the stability of the rotor and cause jumps. Luo et al. [32] studied the nonlinear vibration of a single rotor-bearing system containing SFDs, analyzed the bifurcation phenomenon at different points on the rotor, and compared the dynamic response at different positions; their results showed that the nonlinear force at the support caused both the vibration response and the bifurcations of the spool at different parts to differ. Gooding et al. [33] used experiments and finite element methods to study a highspeed centrifugal compressor for aeroengine applications; their results showed that effective weight of the damper support may change the second critical speed of the rotor system; increasing the weight of the damper, the second critical speed drops rapidly. Ma et al. [34] established a finite element model of an aeroengine dual-rotor system with SFD and carried out a comparative study of the influence of SFD on the response of the rotor's nonlinear system. The research results showed that unreasonable SFD parameters would aggravate the vibration of the system.

The aforementioned studies have shown that the presence of SFDs greatly influences the dynamic responses of engine rotor-bearing systems. Choosing inappropriate SFD parameter values may (i) prevent the vibration response of 


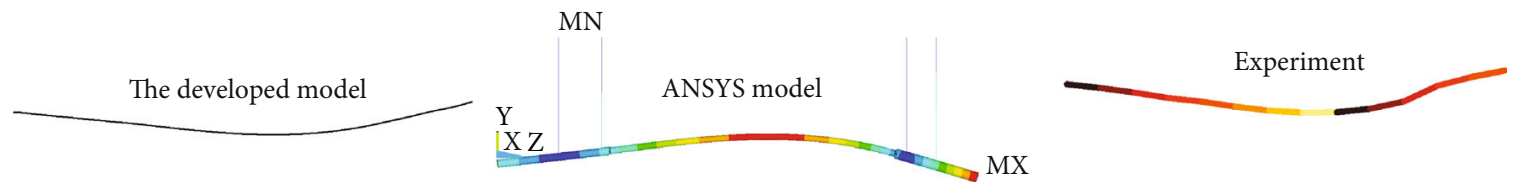

(a)

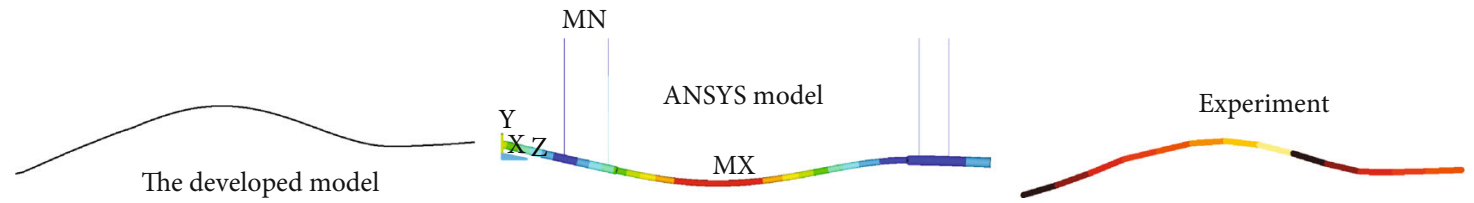

(b)

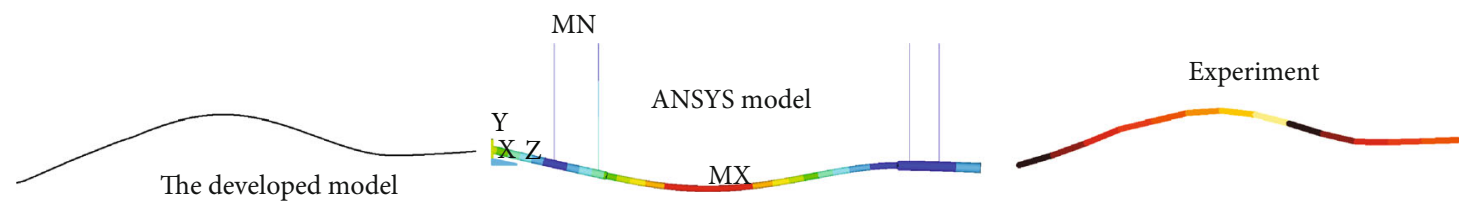

(c)

Figure 8: First three model shape of power-turbine rotor: (a) 1st; (b) 2nd; (c) 3rd.

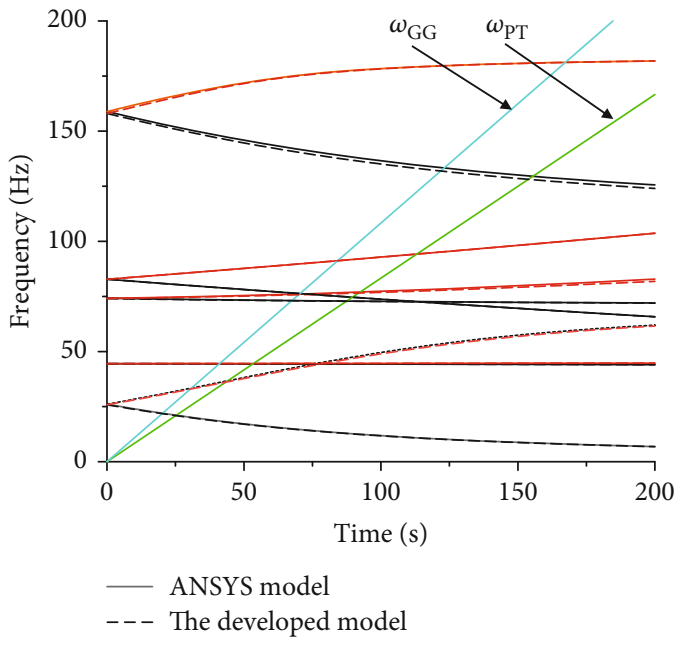

FIgURE 9: Campbell diagram of a system.

the shaft from being reduced and (ii) degrade the response of the rotor-bearing system. Summarizing the research to date, theoretical and experimental research on rotorbearing systems with a turbine SSS remains lacking, and SFDs should be considered when establishing dynamic models of complex rotor-bearing systems. Therefore, it is essential to subject turbine-SSS rotor-bearing systems with SFDs to both modeling and coupling-vibration-response research.

The above research shows that the current articles on the nonlinear vibration of dual-rotor systems mainly focus on the study of dual-rotor systems with intermediate bearings, focusing on the effects of intermediate bearings and other nonlinear factors on the response of the rotor system. The present paper reports on an FE model and a tester of a rotor-bearing system with a turbine SSS and containing SFDs for the first time. The nonlinear dynamic response law of the rotor-bearing system with a turbine SSS and SFDs was studied. The specific research contents are as follows. The tester of a rotor-bearing system with a turbine SSS and SFDs was established in Section 2. In Section 3, the FE model of the tester was proposed, and the unbalance response of the rotor-bearing system was obtained and compared based on the FE model and the tester. The influence of different parameters on the response of the rotor-bearing system was studied in Section 4. Conclusions are drawn in Section 5.

\section{Rotor-Bearing System Model with Shared Support Structure}

2.1. Structure of Turboshaft Engine. A practical turboshaft engine with a turbine SSS is shown in Figure 1. The gas generator (GG) rotor uses the 1-0-1 support scheme with two bearings, namely, bearings 3 and 4, each of which contains an SFD. The PT shaft has four bearings: bearings 1 and 2 are front bearings, bearings 5 and 6 are rear bearings, and bearings 2 and 6 contain SFDs. The turbine SSS supports the rear three bearings of the two rotors simultaneously.

2.2. Structure of Test Rig. Based on the features of the turboshaft engine with a turbine SSS, we designed the test system containing a turbine SSS as shown in Figure 2; Figure 2(a) shows it schematically, and Figure 2(b) shows it photographically. The test system contains two concentric rotating shafts that are connected by a turbine SSS. Each rotating shaft is driven by its own motor so that the two spools can have different working speeds. Bearings 1 and 3 are deepgroove ball bearings that are the axial positioning fulcrums of the PT and GG shafts, respectively, and the other four bearings are all roller bearings; we use the squirrel-cage-rolling-bearing support scheme for bearings 1 and 5 and the 
TABLe 6: Critical speed comparison $(\omega=0 \mathrm{rpm})$.

\begin{tabular}{llcccccccc}
\hline & \multicolumn{2}{c}{ Excitation } & \multicolumn{7}{c}{ Critical speed (rpm) } \\
\hline \multirow{3}{*}{ The developed model } & & 1 st & Error & 2nd & Error & 3rd & Error & 4 th & Error \\
& Gas-generator rotor & 1975 & 0.4 & 2673 & 0 & 4547 & 0.1 & 5472 & 0 \\
\multirow{3}{*}{ ANSYS model } & Power-turbine rotor & 2165 & 0.4 & 2674 & 0 & 4593 & 0.1 & 5653 & 0 \\
& Gas-generator rotor & 1982 & - & 2673 & - & 4551 & - & 4572 & - \\
& Power-turbine rotor & 2173 & - & 2674 & - & 4598 & - & 5653 & - \\
\hline
\end{tabular}

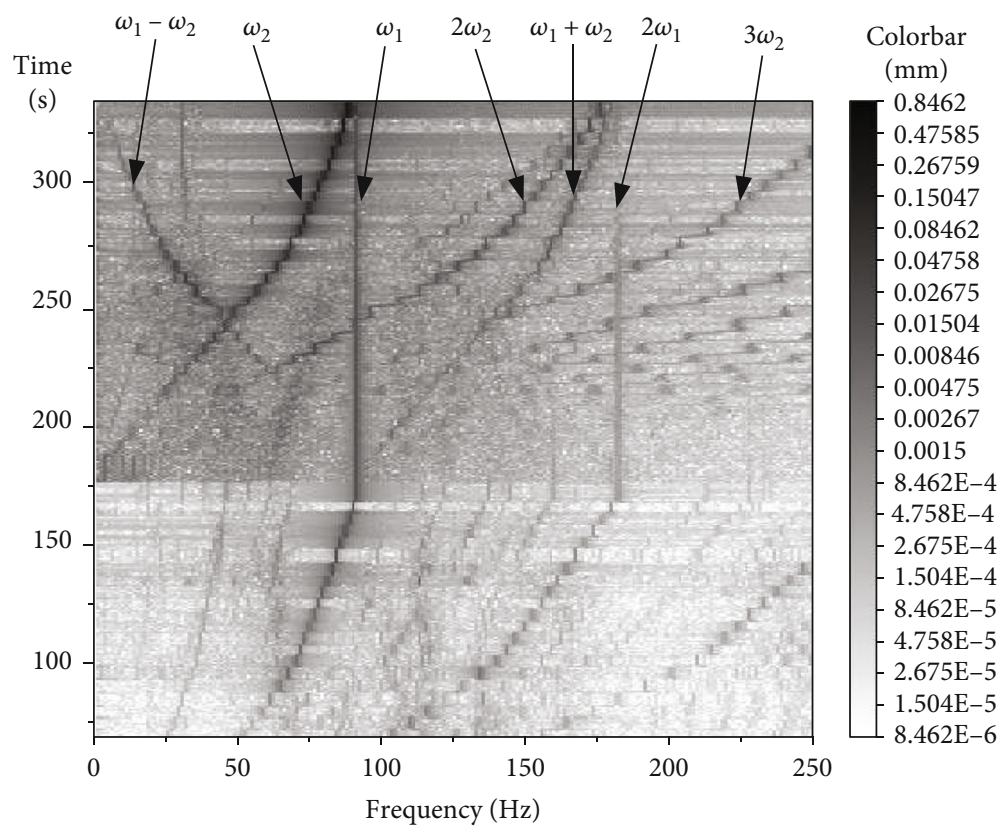

FIgURE 10: Test results: measuring points for power turbine (PT) rotor.

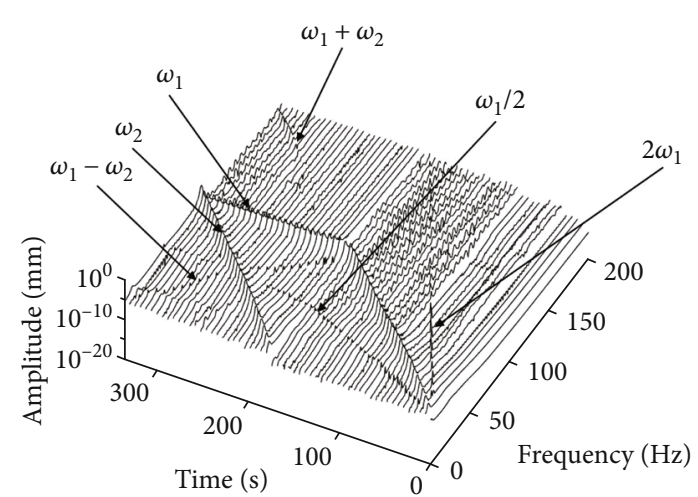

FIGURE 11: Simulation analysis results: measuring points for PT rotor.

squirrel-cage-rolling-bearing-SFD support scheme for the rest. In total, we use eight displacement sensors and two acceleration sensors to monitor the acceleration response of the test system at five axial positions. At a given axial point, one sensor is oriented in the horizontal direction of the rotor-bearing test system and the other is oriented in the vertical direction.

\section{Dynamic Model of Rotor-Bearing System}

3.1. Finite-Element Formulation. Herein, the GG and PT shafts and the SSS are simulated by Timoshenko beam elements. The schematic diagram of the beam element is shown in Figure 3. Each element includes two nodes, and each node has four degrees of freedom, which are the translational degrees of freedom along the $x$-axis and $y$-axis and the rotational degrees of freedom around the $x$-axis and $y$-axis. In Figure $3, n_{1}$ represents node 1 and $n_{2}$ represents node 2 . The translational degrees of freedom of node 1 along the $x$ -axis and $y$-axis are $u_{e 1}$ and $v_{e 1}$. The rotational degrees of freedom of node 1 around the $x$-axis and $y$-axis are $\theta_{e 1}$ and $\varphi_{e 1}$. The subscript $e 1$ represents node 1; by analogy, the degrees of freedom in the four directions of node 2 are $u_{e 2}, v_{e 2}, \theta_{e 2}$, and $\varphi_{e 2}$, respectively. In addition, only the radial shaft vibrations are considered; the axial and torsional ones are ignored. The degrees of freedom of a shaft section are expressed as

$$
\mathbf{q}_{\mathbf{e}}=\left[\begin{array}{llllll}
u_{e 1} & v_{e 1} & \theta_{e 1} & \varphi_{e 1} & u_{e 2} & v_{e 2} \\
\theta_{e 2} \varphi_{e 2}
\end{array}\right]^{T} .
$$

The mass matrix $\mathbf{m}_{\mathbf{e}}$, stiffness matrix $\mathbf{k}_{\mathbf{e}}$, and gyroscopic matrix $\mathbf{g}_{\mathbf{e}}$ of the shaft segment are given in Equations (2)-(5), the derivations of which are given elsewhere [21]. 


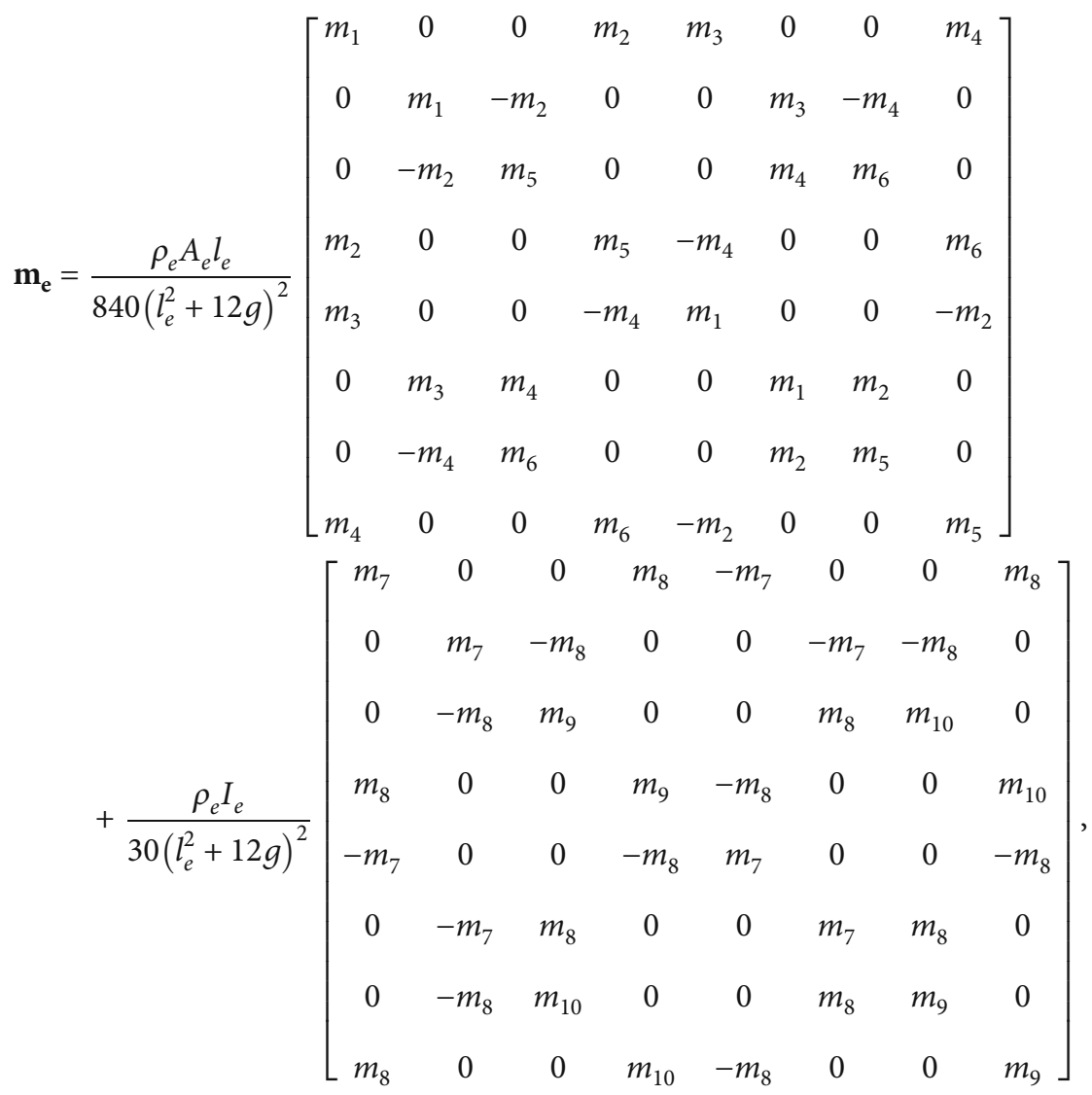

where $\rho_{e}, A_{e}$, and $l_{e}$ are the material density, cross-sectional area, and axial length of the shaft section, respectively, and we write $m_{1}-m_{10}$ as

$$
\begin{aligned}
& \begin{cases}m_{1}=312 l_{e}^{4}+7056 g l_{e}^{2}+40320 g^{2} & m_{6}=-\left(6 l_{e}^{4}+168 g l_{e}^{2}+1008 g^{2}\right) l_{e}^{2}, \\
m_{2}=\left(44 l_{e}^{4}+924 g l_{e}^{2}+5040 g^{2}\right) l_{e} & m_{7}=36 l_{e}^{3}, \\
m_{3}=108 l_{e}^{4}+3024 g l_{e}^{2}+20160 g^{2} & m_{8}=\left(3 l_{e}^{2}-180 g\right) l_{e}^{2}, \\
m_{4}=-\left(26 l_{e}^{4}+756 g l_{e}^{2}+5040 g^{2}\right) l_{e} & m_{9}=\left(4 l_{e}^{4}+60 g l_{e}^{2}+1440 g^{2}\right) l_{e}, \\
m_{5}=\left(8 l_{e}^{4}+168 g l_{e}^{2}+1008 g^{2}\right) l_{e}^{2} & m_{10}=\left(-l_{e}^{4}-60 g l_{e}^{2}+720 g^{2}\right) l_{e},\end{cases} \\
& \mathbf{k}_{\mathbf{e}}=\frac{E_{e} I_{e}}{l_{e}\left(l_{e}^{2}+12 g\right)}\left[\begin{array}{cccccccc}
b_{1} & 0 & 0 & b_{2} & -b_{1} & 0 & 0 & b_{2} \\
0 & b_{1} & -b_{2} & 0 & 0 & -b_{1} & -b_{2} & 0 \\
0 & -b_{2} & b_{3} & 0 & 0 & b_{2} & b_{4} & 0 \\
b_{2} & 0 & 0 & b_{3} & -b_{2} & 0 & 0 & b_{4} \\
-b_{1} & 0 & 0 & -b_{2} & b_{1} & 0 & 0 & -b_{2} \\
0 & -b_{1} & b_{2} & 0 & 0 & b_{1} & b_{2} & 0 \\
0 & -b_{2} & b_{4} & 0 & 0 & b_{2} & b_{3} & 0 \\
b_{2} & 0 & 0 & b_{4} & -b_{2} & 0 & 0 & b_{3}
\end{array}\right] \text {, }
\end{aligned}
$$




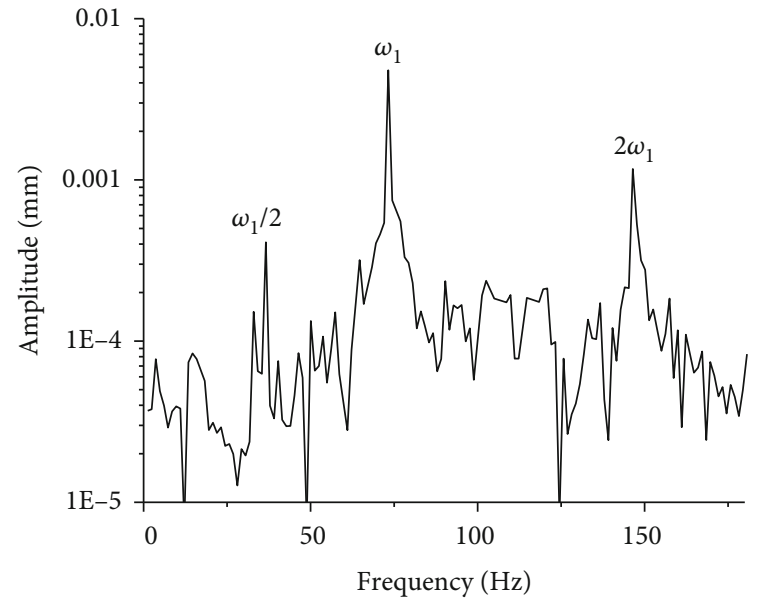

(a)

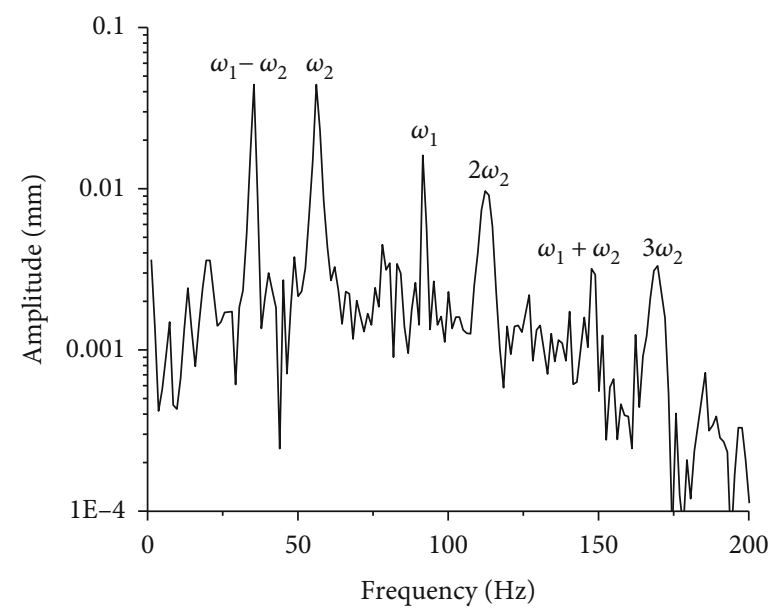

(c)

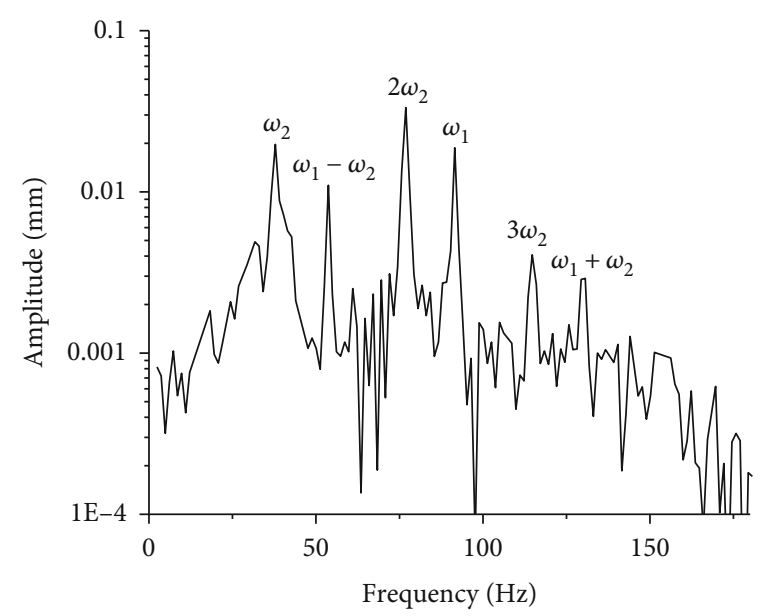

(b)

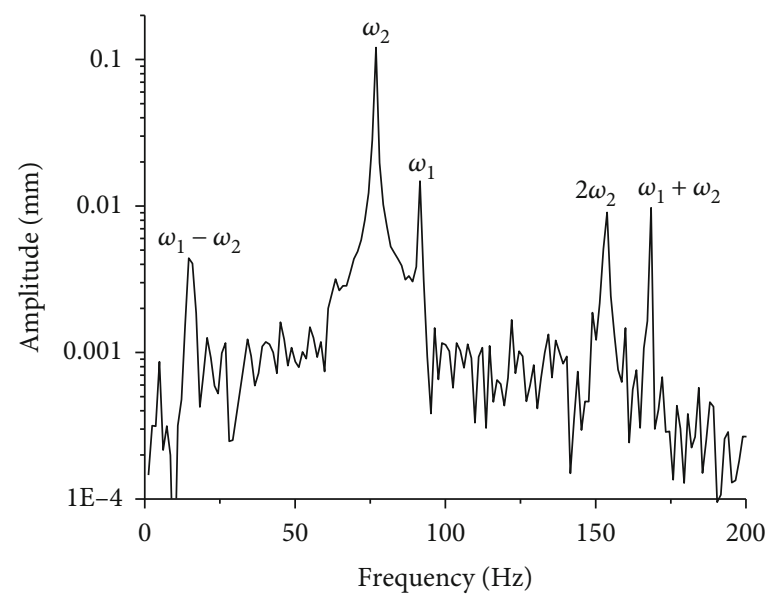

(d)

Figure 12: Test results: the 2D spectrum map at different times: (a) $70 \mathrm{~s}$; (b) $240 \mathrm{~s}$; (c) $280 \mathrm{~s}$; (d) $310 \mathrm{~s}$.

where $E_{e}$ is the modulus of elasticity and $b_{1}, b_{2}, b_{3}$, and $b_{4}$ are formulated as $b_{1}=12, b_{2}=6 l_{e}, b_{3}=4 l_{e}^{2}+12 g$, and $b_{4}=2$ $l_{e}^{2}-12 g$ :

$$
\mathbf{g}_{\mathbf{e}}=\frac{\rho_{e} I_{e}}{15\left(l_{e}^{2}+12 g\right)^{2}}\left[\begin{array}{cccccccc}
0 & g_{1} & -g_{2} & 0 & 0 & -g_{1} & -g_{2} & 0 \\
-g_{1} & 0 & 0 & -g_{2} & g_{1} & 0 & 0 & -g_{2} \\
g_{2} & 0 & 0 & g_{3} & -g_{2} & 0 & 0 & g_{4} \\
0 & g_{2} & -g_{3} & 0 & 0 & -g_{2} & -g_{4} & 0 \\
0 & -g_{1} & g_{2} & 0 & 0 & g_{1} & g_{2} & 0 \\
g_{1} & 0 & 0 & g_{2} & -g_{1} & 0 & 0 & g_{2} \\
g_{2} & 0 & 0 & g_{4} & -g_{2} & 0 & 0 & g_{3} \\
0 & g_{2} & -g_{4} & 0 & 0 & -g_{2} & -g_{3} & 0
\end{array}\right] .
$$




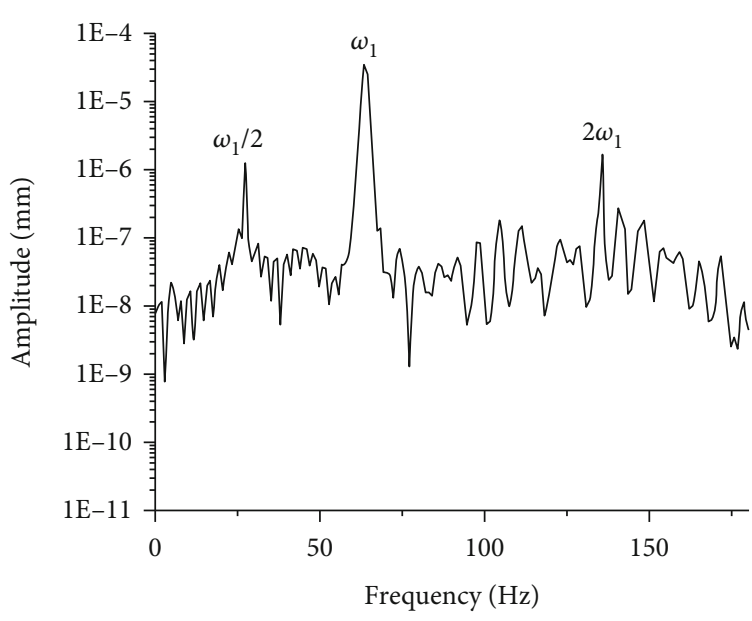

(a)

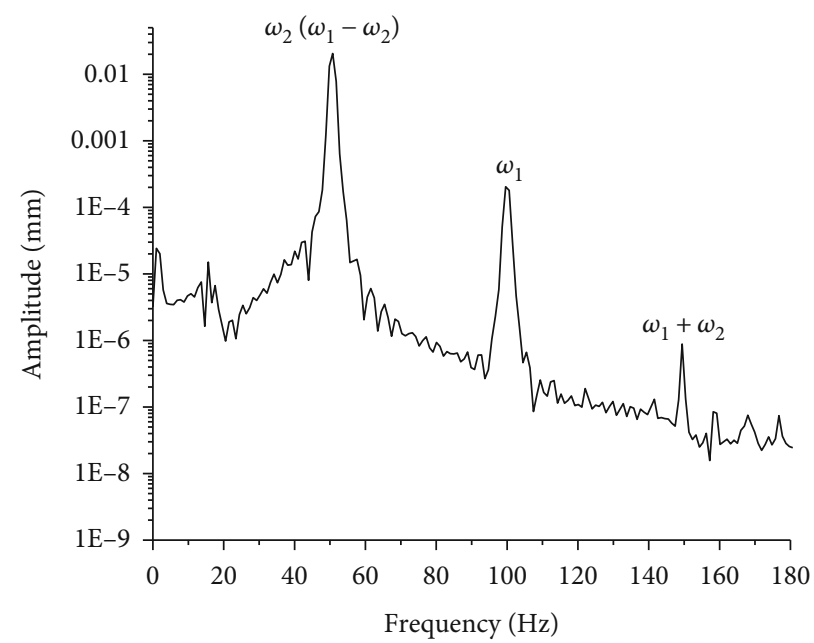

(c)

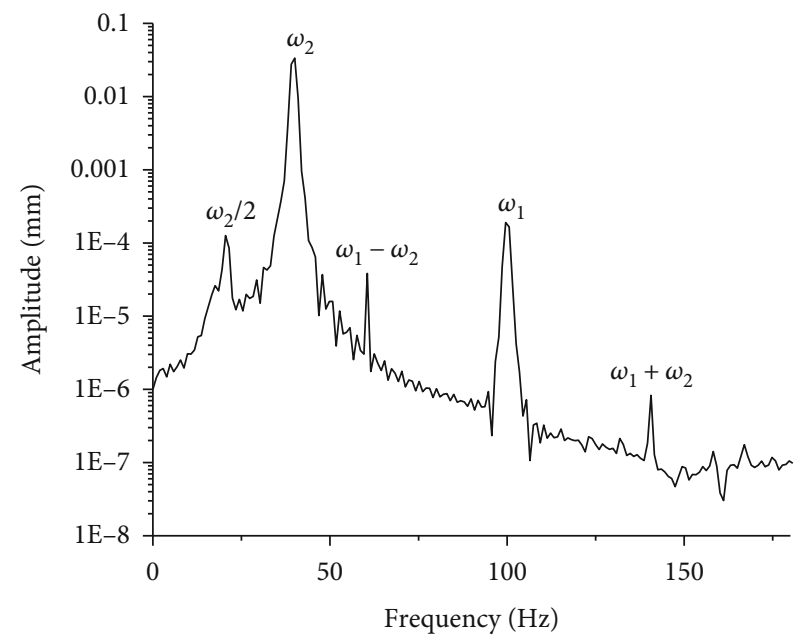

(b)

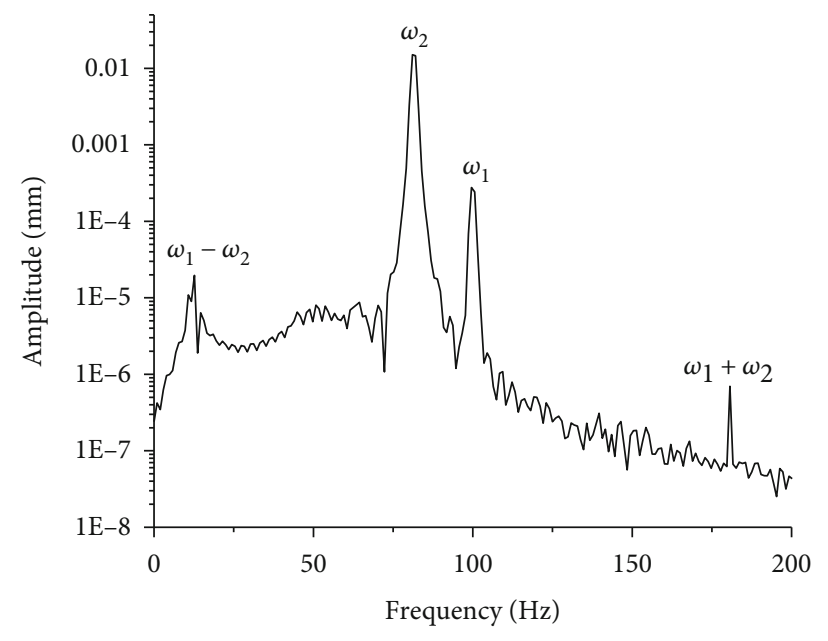

(d)

FIGURE 13: Simulation analysis results: the 2D spectrum map at different times: (a) $75 \mathrm{~s}$; (b) $243 \mathrm{~s}$; (c) $282 \mathrm{~s}$; (d) $310 \mathrm{~s}$.

All disk is simulated as a concentrated mass unit that accounts for the gyroscopic effect. The mass matrix $\mathbf{m}_{\mathbf{e}}^{\mathbf{d}}$ and gyroscopic matrix $\mathbf{g}_{\mathbf{e}}^{\mathbf{d}}$ of the disk are expressed as

$$
\begin{aligned}
& \mathbf{m}_{\mathbf{e}}^{\mathbf{d}}=\left[\begin{array}{cccc}
m_{d} & 0 & 0 & 0 \\
0 & m_{d} & 0 & 0 \\
0 & 0 & I_{d} & 0 \\
0 & 0 & 0 & I_{d}
\end{array}\right], \\
& \mathbf{g}_{\mathbf{e}}^{\mathbf{d}}=\left[\begin{array}{cccc}
0 & 0 & 0 & 0 \\
0 & 0 & 0 & 0 \\
0 & 0 & 0 & I_{p} \\
0 & 0 & -I_{p} & 0
\end{array}\right],
\end{aligned}
$$

where $m_{d}, I_{d}$, and $I_{p}$ are the mass, diametral moment, and polar moment of inertia of the disk, respectively.
TABle 7: Unbalance of PT rotor.

\begin{tabular}{llllll}
\hline Model & 1 & 2 & 3 & 4 & 5 \\
\hline Unbalance $(\mathrm{g} \cdot \mathrm{cm})$ & 1 & 3 & 5 & 7 & 9 \\
\hline
\end{tabular}

3.2. Equations of Motion for a Rotor-Bearing System. The nonlinear dynamic equations of a rotor-bearing system can be expressed as

$$
\mathbf{M} \ddot{\mathbf{u}}+\mathbf{G} \dot{\mathbf{u}}+\mathbf{K u}=\mathbf{F}^{e}+\mathbf{F}^{f},
$$

where $\mathbf{M}, \mathbf{G}$, and $\mathbf{K}$ are the mass, gyroscopic, and stiffness matrices of the rotor-bearing system, respectively, which can be obtained according to the method in Section 3.1. Here, $\mathbf{u}$ is the displacement vector of the rotor-bearing system, $\mathbf{F}^{e}$ is the unbalanced force, and $\mathbf{F}^{f}$ is the nonlinear force introduced by an SFD. The unbalanced force $\mathbf{F}^{e}$ is expressed as 

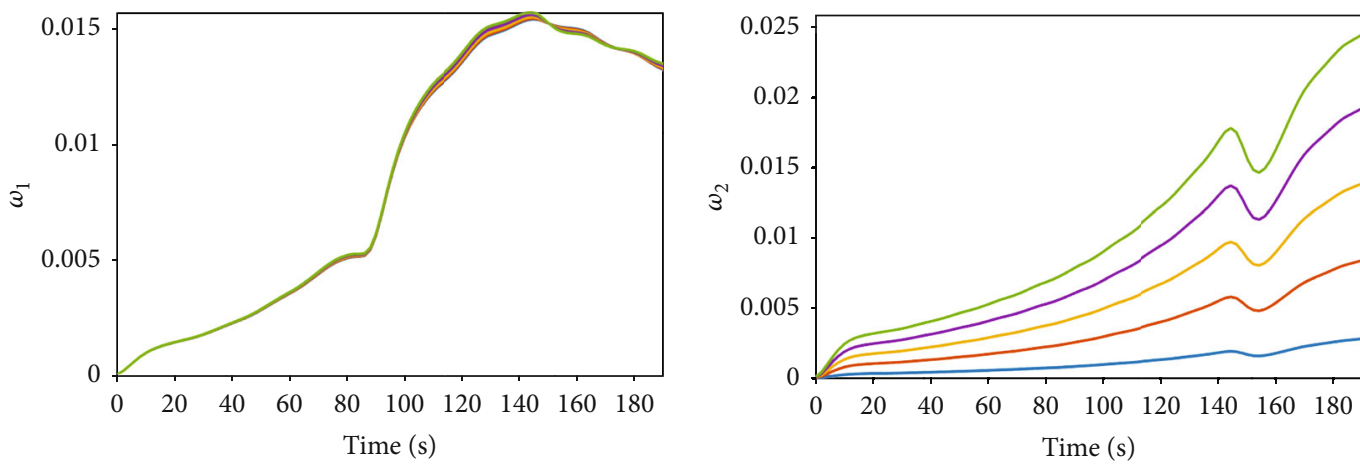

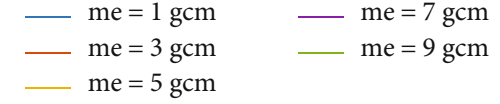

(a)

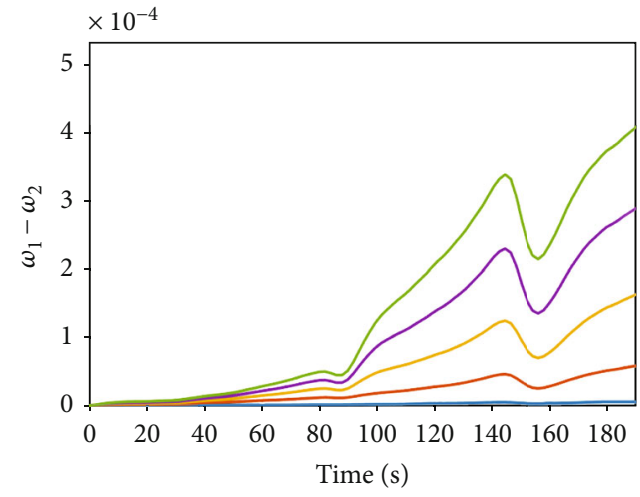

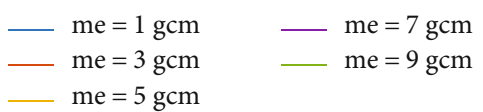

(c)

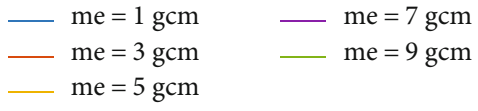

(b)

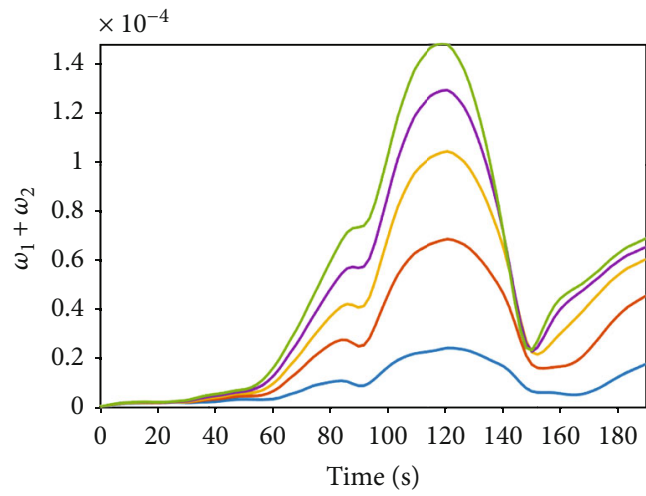

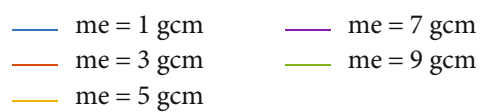

(d)

FIGURE 14: Responses at the analysis node of PT rotor with influence of PT rotor unbalance: (a) $\omega_{1}$; (b) $\omega_{2}$; (c) $\omega_{1}-\omega_{2}$; (d) $\omega_{1}+\omega_{2}$.

$$
\mathbf{F}^{e}=\left\{\begin{array}{l}
m e \omega^{2} \sin \left(\omega t+\varphi_{0}\right), \\
m e \omega^{2} \cos \left(\omega t+\varphi_{0}\right),
\end{array}\right.
$$

where $m$ is the unbalanced mass, $e$ is its eccentricity, $\varphi_{0}$ is its initial phase, and $\omega$ is the angular velocity of the spool.

The nonlinear force introduced by an SFD can be obtained by integrating the pressure distribution along with the circumferential and axial directions $[35,36]$.

$$
\left\{\begin{array}{c}
f_{x}^{s}=-\frac{\mu_{s} R L^{3}}{c^{2} \sqrt{\left(x^{2}+y^{2}\right)}}\left[x\left(\dot{\varepsilon} I_{2}+\varepsilon \dot{\psi} I_{1}\right)-y\left(\dot{\varepsilon} I_{1}+\varepsilon \dot{\psi} I_{3}\right)\right], \\
f_{y}^{s}=-\frac{\mu_{s} R L^{3}}{c^{2} \sqrt{\left(x^{2}+y^{2}\right)}}\left[y\left(\dot{\varepsilon} I_{2}+\varepsilon \dot{\psi} I_{1}\right)+x\left(\dot{\varepsilon} I_{1}+\varepsilon \dot{\psi} I_{3}\right)\right], \\
\varepsilon=\frac{\sqrt{x^{2}+y^{2}}}{c},
\end{array}\right.
$$

$$
\begin{gathered}
\dot{\varepsilon}=\frac{(x \dot{x}+y \dot{y})}{\left(c \sqrt{x^{2}+y^{2}}\right)}, \\
\dot{\psi}=\frac{(y \dot{x}-x \dot{y})}{\left(x^{2}+y^{2}\right)}, \\
\tan \psi=\frac{y}{x}
\end{gathered}
$$

where $x$ and $y$ are the horizontal and vertical displacements, respectively, of the shaft diameter, $L$ is the axial width of the $\mathrm{SFD}, R$ is the average radius of the SFD, $c$ is the SFD radius clearance, $\mu$ is the dynamic viscosity of the oil, and $I_{1}, I_{2}$, and $I_{3}$ are Sommerfeld integrals which can be expressed as

$$
\begin{aligned}
& I_{1}=\int_{\theta_{1}}^{\theta_{1}+\pi} \frac{\cos ^{2} \theta}{(1+\varepsilon \cos \theta)^{3}} d \theta, \\
& I_{2}=\int_{\theta_{1}}^{\theta_{1}+\pi} \frac{\sin \theta \cos \theta}{(1+\varepsilon \cos \theta)^{3}} d \theta,
\end{aligned}
$$



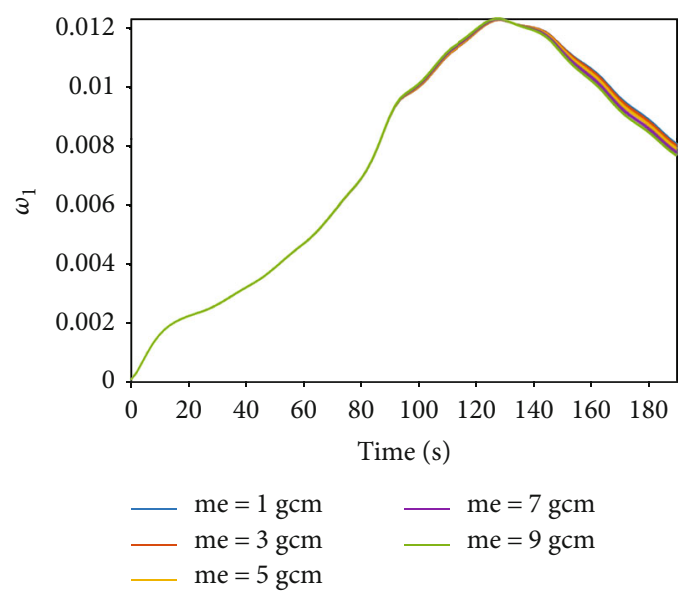

(a)

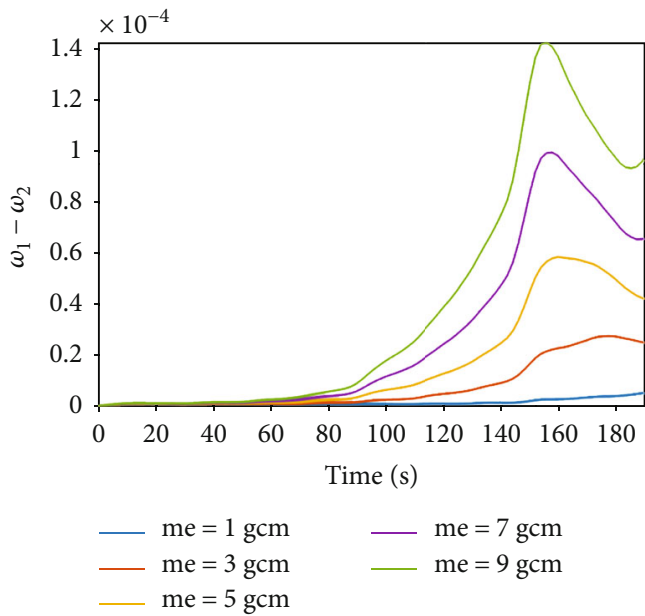

(c)

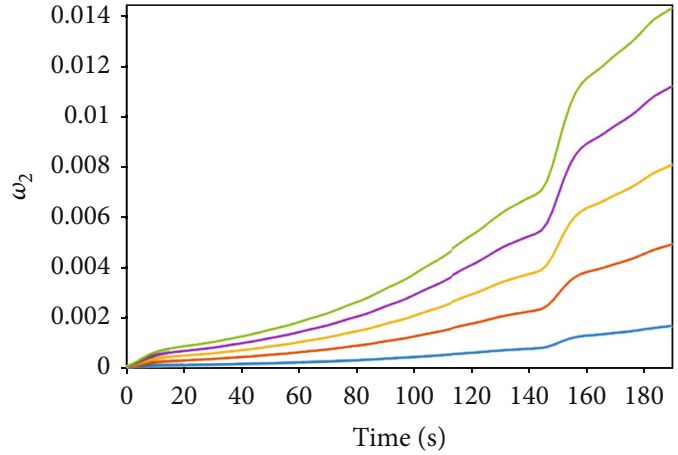

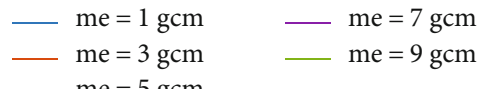

(b)

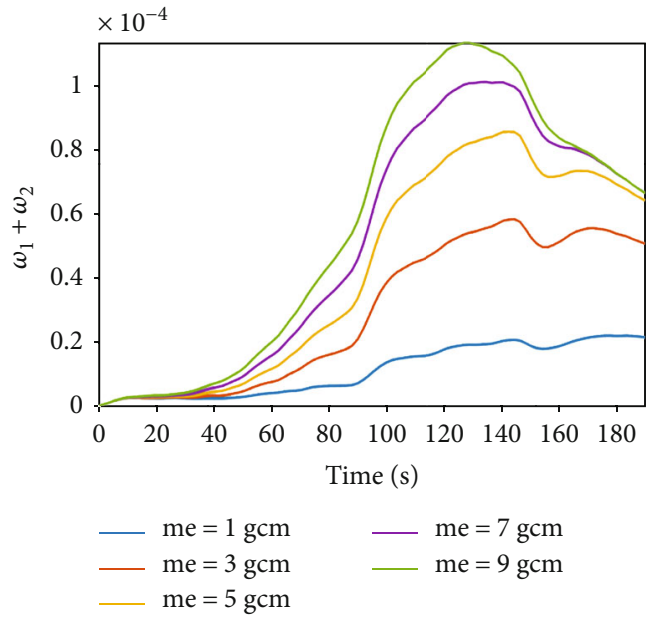

(d)

FIGURE 15: Responses at the analysis node of GG rotor with influence of PT rotor unbalance: (a) $\omega_{1}$; (b) $\omega_{2}$; (c) $\omega_{1}-\omega_{2}$; (d) $\omega_{1}+\omega_{2}$.

$$
\begin{gathered}
I_{3}=\int_{\theta_{1}}^{\theta_{1}+\pi} \frac{\sin ^{2} \theta}{(1+\varepsilon \cos \theta)^{3}} d \theta, \\
\theta_{1}=\tan ^{-1}\left(-\frac{\dot{\varepsilon}}{\varepsilon \dot{\phi}}\right) .
\end{gathered}
$$

Herein, we treat the squirrel cage as an isotropic linear spring whose stiffness is set directly, and we ignore the stiffness and damping of the rolling bearings. Having established the dynamic model of the rotor-bearing system, we use the implicit Newmark- $\beta$ method to solve for its response. The modeling and solution process is shown in Figure 4.

3.3. Finite-Element Model. The simplified analysis model of the test system is shown schematically in Figure 5; among them, the PT rotor includes 5 parts with a total length of $1133.93 \mathrm{~mm}$, which is divided into 114 nodes and 113 elements along the axial direction. The node numbers are 1114. The GG rotor includes 4 parts with a total length of $1133.93 \mathrm{~mm}$, which is divided into 71 nodes and 70 elements along the axial direction. The node numbers are 115-186. The total length of the SSS is $187 \mathrm{~mm}$, and it is divided into 19 nodes and 18 elements along the axial direction. The
TABLE 8: Radial stiffness of shared support structure (SSS).

\begin{tabular}{lccccc}
\hline Model & 1 & 2 & 3 & 4 & 5 \\
\hline$k_{x x}(\mathrm{~N} / \mathrm{m})$ & $5 \times 10^{6}$ & $1 \times 10^{7}$ & $5 \times 10^{7}$ & $1 \times 10^{8}$ & $5 \times 10^{8}$ \\
\hline
\end{tabular}

node numbers are 187-205. The node numbers of the disks and bearings are shown in Tables 1 and 2, respectively. The structural parameter values for the shafts, disks, squirrel cages, and SFDs are given in Tables 3, 1, 2, and 4, respectively. Among them, the structural parameters of the shafts, disks, and SFDs are determined by the results of the tester design stage, and the stiffness values of squirrel cages are determined by the static stiffness test. In Table 2, supports 1-6 are shaft supports with only their radial stiffness $\left(k_{x x}\right.$, $\left.k_{y y}\right)$ considered. Support 7 is the support of the turbine SSS, with both radial stiffness $\left(k_{x x}, k_{y y}\right)$ and bending stiffness $\left(k_{x z}, k_{y z}\right)$ considered. In the model established herein, we suppose that $k_{x x}=k_{y y}$ and $k_{x z}=k_{y z}$.

3.4. Verification of the Rotor-Bearing System Model. In order to verify the model established in this paper, we propose the 

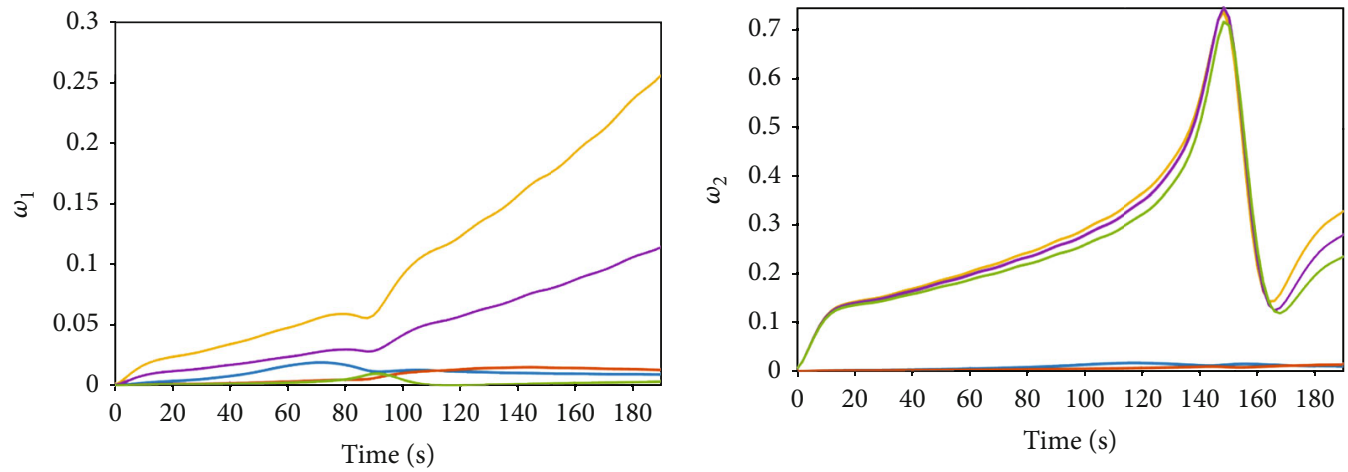

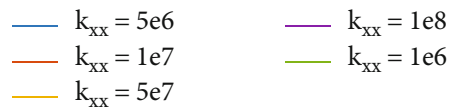

(a)
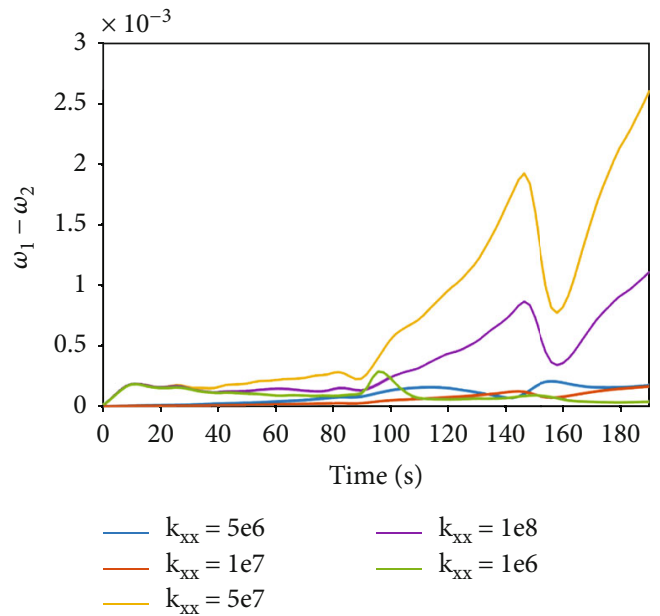

(c)

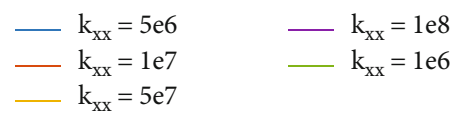

(b)
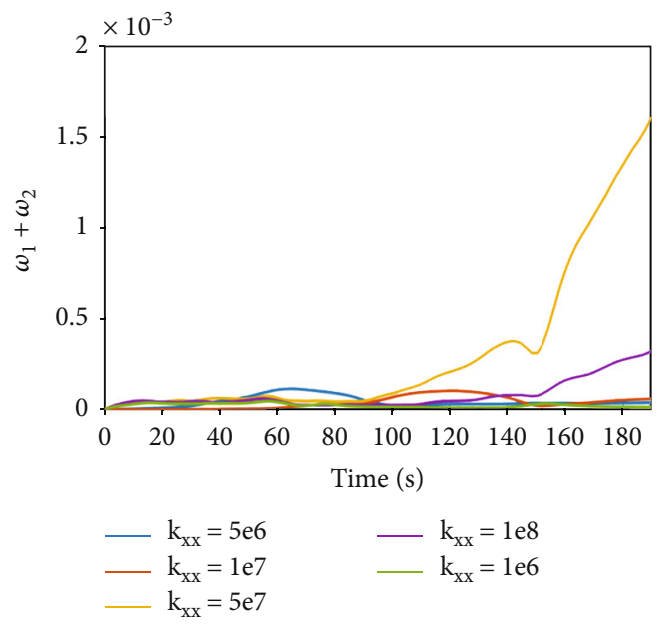

(d)

FIGURE 16: Responses at the analysis node of PT rotor with influence of radial stiffness of SSS: (a) $\omega_{1}$; (b) $\omega_{2}$; (c) $\omega_{1}-\omega_{2}$; (d) $\omega_{1}+\omega_{2}$.

following work: single-rotor modal verification based on experiment and simulation, dual-rotor critical speed verification based on simulation methods under linear conditions, and dual-rotor unbalance response verification based on experimental methods under nonlinear conditions.

The first three-order natural frequencies of the GG rotor and PT rotor obtained by using the developed model in this paper, the solid185 model in ANSYS, and the experiment are shown in Table 5. The maximum relative error between the predicted results of the developed model and the experimental results is about 6.1\%. The test model is shown in Figure 6, and the vibration shapes obtained from the three models are shown in Figures 7 and 8. It can be seen that due to the existence of the squirrel cage support and the larger shaft diameter of the GG rotor, the bending stiffness of the GG rotor is greater. Therefore, the first two order modes of vibration are cylindrical and conical, and the third is the bending mode. The PT rotor is a slender rotor, and the bearing 1 and bearing 2 supports are a group, and the bearing 5 and bearing 6 supports are a group. The local bending stiffness of the two ends of the PT rotor is relatively large, so the first three order vibration modes of the PT rotor all show a bending vibration shape.

The Campbell diagram obtained through the model developed in this paper and the ANSYS model is shown in Figure 9. The red curve in the figure represents forward precession, and the black curve represents backward precession. PT rotor speed range is $0 \sim 10000 \mathrm{rpm}$, and GG rotor speed range is $0 \sim 13000 \mathrm{rpm}$. It should be noted that in order to decrease the computation burden, the beam 188 element in ANSYS was selected to establish a linear finite element model of the tester for comparison. The bending stiffness of bearing 7 on SSS is replaced by the torsional stiffness of the conbin 14 element built on the side of the SSS. The critical speeds obtained by the two methods are shown in Table 6. Since the element selected for modeling in this paper is consistent with the element adopted in ANSYS modeling and the mesh size is consistent, the Campbell diagram is in good agreement, and the maximum error of the critical speed is only $0.4 \%$.

Through the above work, the accuracy of the rotor system model under linear conditions is verified, and then, 

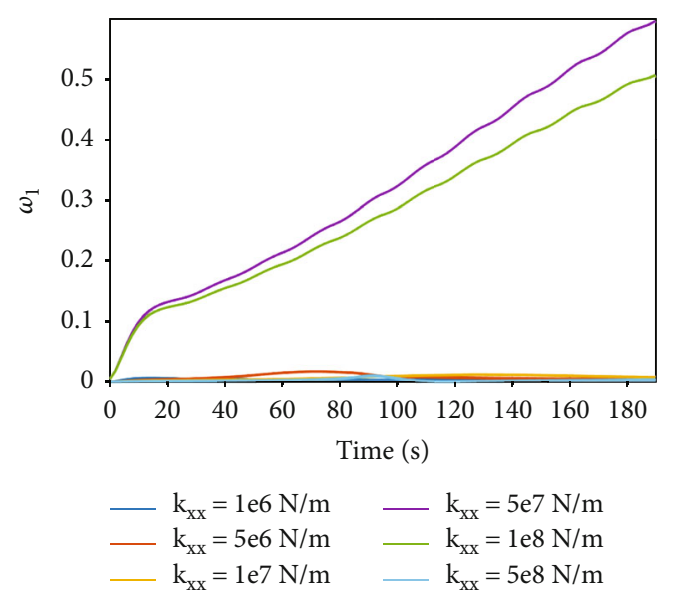

(a)
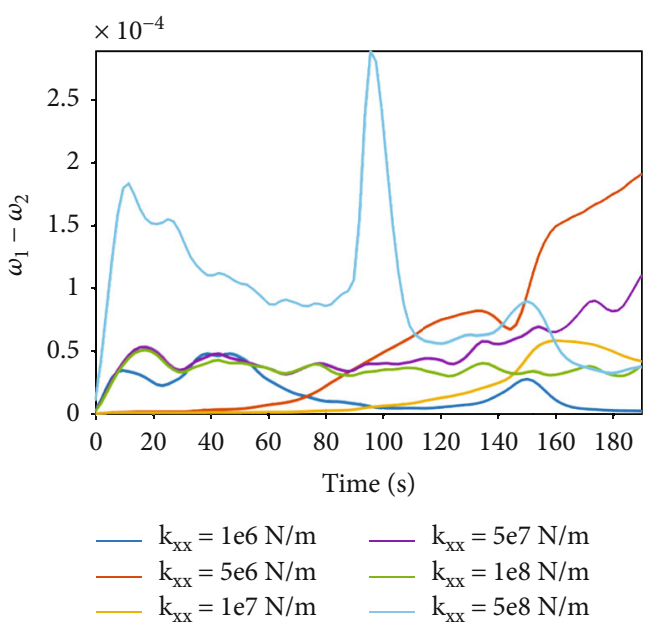

(c)

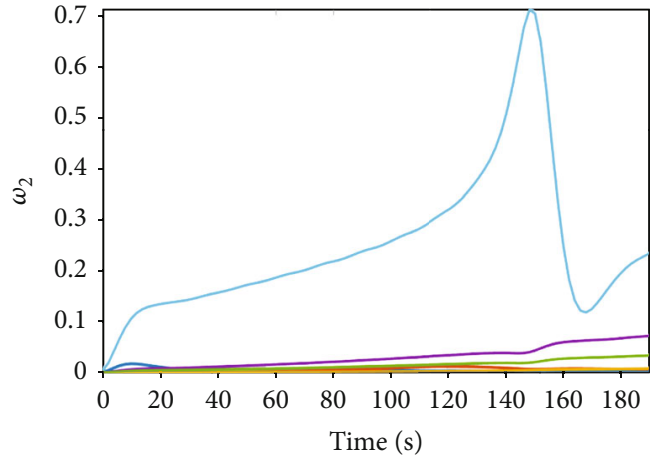

$$
\begin{aligned}
& -\mathrm{k}_{\mathrm{xx}}=1 \mathrm{e} 6 \mathrm{~N} / \mathrm{m}-\mathrm{k}_{\mathrm{xx}}=5 \mathrm{e} 7 \mathrm{~N} / \mathrm{m} \\
& \mathrm{k}_{\mathrm{xx}}=1 \mathrm{e} 7 \mathrm{~N} / \mathrm{m} \longrightarrow \mathrm{k}_{\mathrm{xx}}=5 \mathrm{e} 8 \mathrm{~N} / \mathrm{m}
\end{aligned}
$$

(b)

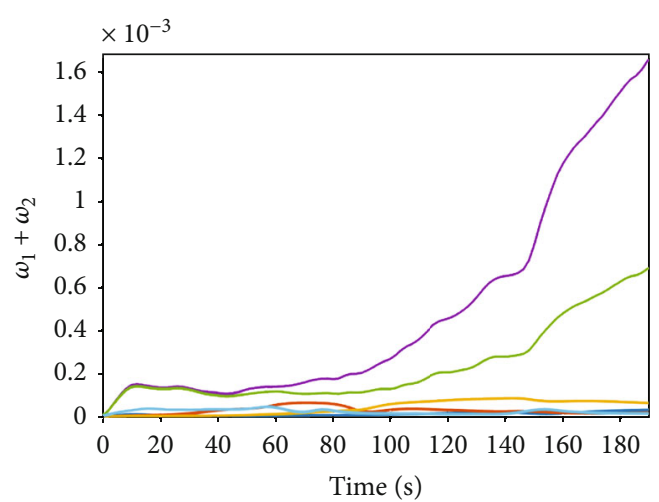

$$
\begin{array}{r}
\mathrm{k}_{\mathrm{xx}}=1 \mathrm{e} 6 \mathrm{~N} / \mathrm{m} \\
\mathrm{k}_{\mathrm{xx}}=5 \mathrm{e} 6 \mathrm{~N} / \mathrm{m} \\
\mathrm{k}_{\mathrm{xx}}=1 \mathrm{e} 7 \mathrm{~N} / \mathrm{m} \quad \mathrm{k}_{\mathrm{xx}}=5 \mathrm{e} 7 \mathrm{~N} / \mathrm{m} \\
\mathrm{k}_{\mathrm{xx}}=1 \mathrm{e} 8 \mathrm{~N} / \mathrm{m} \\
\mathrm{k}_{\mathrm{xx}}=5 \mathrm{e} 8 \mathrm{~N} / \mathrm{m}
\end{array}
$$

(d)

Figure 17: Responses at the analysis node of GG rotor with influence of radial stiffness of SSS: (a) $\omega_{1}$; (b) $\omega_{2}$; (c) $\omega_{1}-\omega_{2}$; (d) $\omega_{1}+\omega_{2}$.

TABLE 9: Bending stiffness of SSS.

\begin{tabular}{lccccc}
\hline Model & 1 & 2 & 3 & 4 & 5 \\
\hline$k_{x z}(\mathrm{~N} \cdot \mathrm{m} / \mathrm{rad})$ & $1 \times 10^{4}$ & $1 \times 10^{5}$ & $1 \times 10^{6}$ & $1 \times 10^{7}$ & $1 \times 10^{8}$ \\
\hline
\end{tabular}

the nonlinear rotor system model is verified. Based on the rotor-bearing test system in Section 2.2 and the FE model established in Section 3.3, we obtain the unbalanced response of the test system by rotor-bearing tests and simulation analysis. We compare the responses obtained by the two methods, thereby verifying the accuracy of the dynamic model established by the FE method developed in this article. Because the regular response patterns in the horizontal and vertical directions are the same, without loss of generality, we take the horizontal response as the example for comparative analysis. Figure 10 shows the grayscale image of the horizontal-direction test results obtained from the measuring points on the PT rotors, and Figure 11 shows the horizontal responses obtained by the $\mathrm{FE}$ method from the measuring points on the rotor-bearing system. In Figures 10 and 11, $\omega_{1}$ and $\omega_{2}$ are the fundamental frequencies of the GG and PT spools, respectively. In addition, the $2 \mathrm{D}$ spectrum map of the test results and the simulation analysis results at different times are shown in Figures 12 and 13, respectively.

For safety reasons, the dual-rotor speeds in the tests were increased in two steps: in step $1(0 s \sim 175 \mathrm{~s})$, the GG spool speed was increased from zero to $6000 \mathrm{rpm}$ while the PT spool remained stationary; in step 2 (180s 340s), the GG spool speed remained at $6000 \mathrm{rpm}$ while the PT spool speed was increased from zero to $6000 \mathrm{rpm}$. During the simulation analysis, the speed law of the GG rotor and the PT rotor is consistent with the experiment.

In both the tests and the FE analysis, the results show that the turbine-SSS rotor system with SFDs has coupling frequency components of $\omega_{1}-\omega_{2}$ and $\omega_{1}+\omega_{2}$, and the results are consistent. Comparing the test and analysis results verifies the accuracy of the analysis model established in Section 3.3.

\section{Simulation Analysis Results of a Rotor- Bearing System}

Based on the validated finite analysis model in Section 3.4, we subject the turbine-SSS dual-rotor system to coupling 

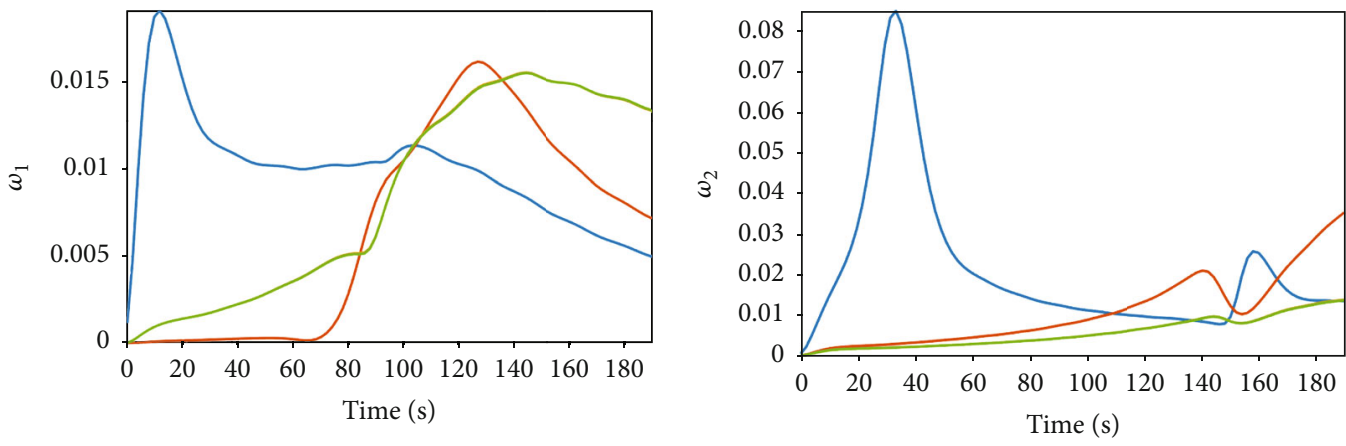

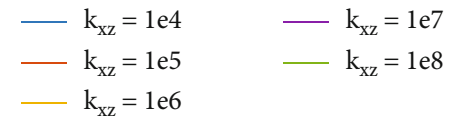

(a)

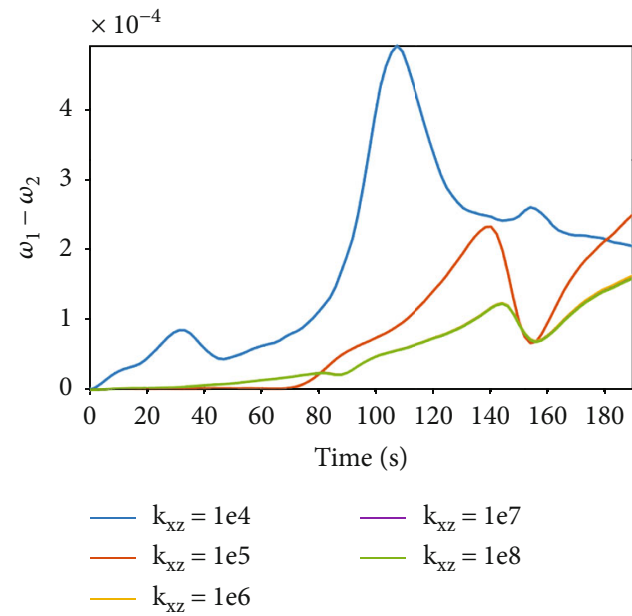

(c)

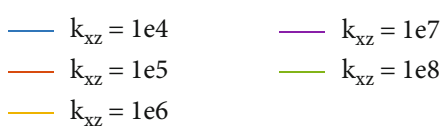

(b)

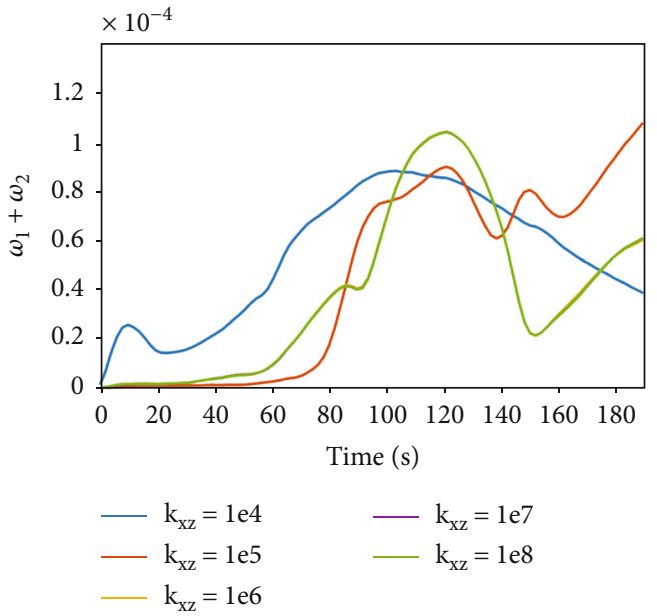

(d)

FIGURE 18: Responses at the analysis node of PT rotor with influence of bending stiffness of SSS: (a) $\omega_{1}$; (b) $\omega_{2}$; (c) $\omega_{1}-\omega_{2}$; (d) $\omega_{1}+\omega_{2}$.

vibration research; the analysis nodes selected in this work are the nodes at disk 5 on the GG rotor and the rightmost node on the PT rotor, which correspond to the measurement points of the outer rotor and the inner rotor in Figure 2(a), respectively.

The parameters studied in this section are the unbalance of the PT rotor, the radial and bending stiffnesses of the SSS $\left(k_{x x}\right.$ and $\left.k_{x z}\right)$, and the radial clearances of SFDs 4 and 6 . We also analyze the regular influence patterns of each parameter on the amplitudes of the four frequency components of $\omega_{1}$, $\omega_{2}, \omega_{1}-\omega_{2}$, and $\omega_{1}+\omega_{2}$. What is more, to avoid encountering harmonics such as multiples of $0.5,1.5$, or 2 , we set the GG rotor speed to be 1.3 times the PT one, $\omega_{1}=1.3 \omega_{2}$.

4.1. Influence of Unbalance of Power-Turbine Rotor. The unbalance of the PT rotor is given in Table 7, and the other calculation parameters of the dynamic model are consistent with those of the model in Section 3.3. The responses at the analysis nodes of the PT rotor of the SSS dual-rotor system are shown in Figure 14 for different values of the PT unbalance; Figures 14(a)-14(d) show the responses of $\omega_{1}, \omega_{2}, \omega_{1}$ $-\omega_{2}$, and $\omega_{1}+\omega_{2}$, respectively. The responses at the analy- sis nodes of the GG rotor of the SSS rotor-bearing system are shown in Figure 15; Figures 15(a)-15(d) show the responses of $\omega_{1}, \omega_{2}, \omega_{1}-\omega_{2}$, and $\omega_{1}+\omega_{2}$, respectively.

Figures 14 and 15 show that the unbalance of the PT rotor has little influence on the amplitude corresponding to $\omega_{1}$ at the analysis nodes of the PT and GG rotors but a greater influence on the responses corresponding to $\omega_{2}, \omega_{1}$ $-\omega_{2}$, and $\omega_{1}+\omega_{2}$. The responses corresponding to the latter three frequency components all increase with increasing unbalance of the PT rotor. When the unbalance of the PT rotor is small, the responses corresponding to $\omega_{1}-\omega_{2}$ and $\omega_{1}+\omega_{2}$ are extremely small and almost negligible. Therefore, we reason that exerting strict control over the spool unbalance is an effective way to control the coupling vibration response of the SSS rotor-bearing system.

4.2. Influence of Radial Stiffness of Shared Support Structure. The radial stiffness of the SSS is given in Table 8 , and the radial stiffness value range of SSS refers to the maximum and minimum stiffness allowed in the design stage of the tester. And the other calculation parameters of the dynamic model are consistent with those of the model in Section 3.3. 


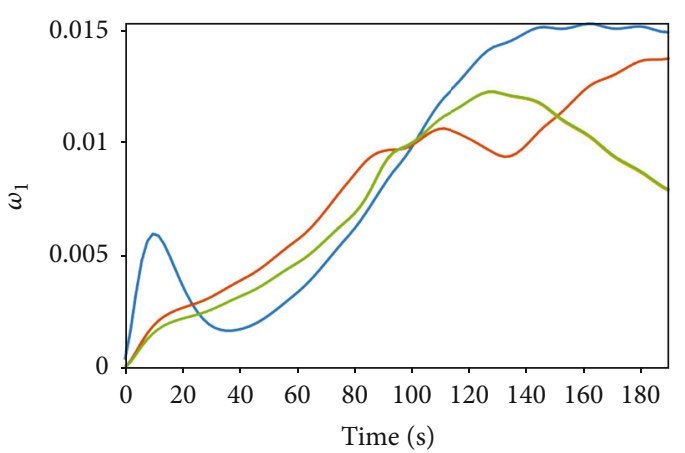

$$
\begin{aligned}
\mathrm{k}_{\mathrm{xz}} & =1 \mathrm{e} 4 \mathrm{~N} / \mathrm{m} \quad-\mathrm{k}_{\mathrm{xz}}=1 \mathrm{e} 7 \mathrm{~N} / \mathrm{m} \\
-\mathrm{k}_{\mathrm{xz}} & =1 \mathrm{e} 5 \mathrm{~N} / \mathrm{m} \\
\mathrm{k}_{\mathrm{xz}} & =1 \mathrm{e} 6 \mathrm{~N} / \mathrm{m}
\end{aligned} \quad-\mathrm{k}_{\mathrm{xz}}=1 \mathrm{e} 8 \mathrm{~N} / \mathrm{m}
$$

(a)

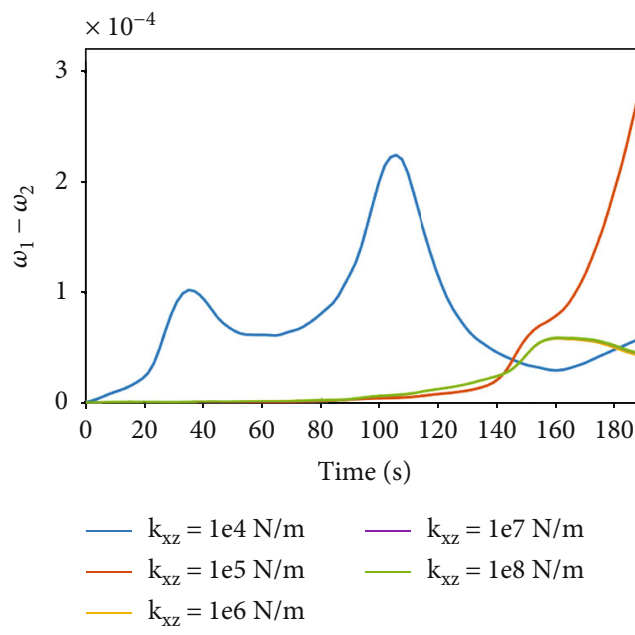

(c)

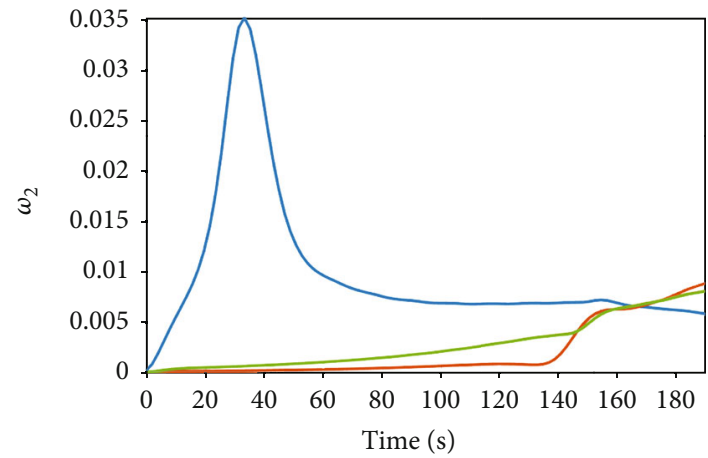

$$
\begin{aligned}
\mathrm{k}_{\mathrm{xz}} & =1 \mathrm{e} 4 \mathrm{~N} / \mathrm{m} \quad-\mathrm{k}_{\mathrm{xz}}=1 \mathrm{e} 7 \mathrm{~N} / \mathrm{m} \\
\mathrm{k}_{\mathrm{xz}} & =1 \mathrm{e} 5 \mathrm{~N} / \mathrm{m} \\
\mathrm{k}_{\mathrm{xz}} & =1 \mathrm{e} 6 \mathrm{~N} / \mathrm{m}
\end{aligned} \quad \mathrm{k}_{\mathrm{xz}}=1 \mathrm{e} 8 \mathrm{~N} / \mathrm{m}
$$

(b)

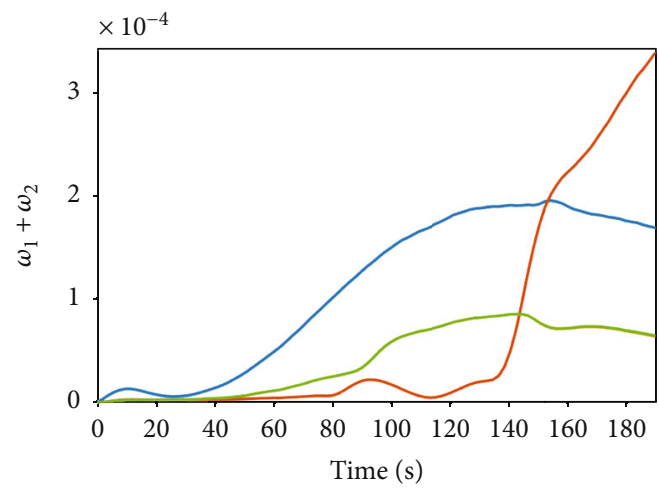

$$
\begin{aligned}
& -\mathrm{k}_{\mathrm{xz}}=1 \mathrm{e} 4 \mathrm{~N} / \mathrm{m}-\mathrm{k}_{\mathrm{xz}}=1 \mathrm{e} 7 \mathrm{~N} / \mathrm{m} \\
& -\mathrm{k}_{\mathrm{xz}}=1 \mathrm{e} 5 \mathrm{~N} / \mathrm{m} \longrightarrow \mathrm{k}_{\mathrm{xz}}=1 \mathrm{e} 8 \mathrm{~N} / \mathrm{m} \\
& \mathrm{k}_{\mathrm{xz}}=1 \mathrm{e} 6 \mathrm{~N} / \mathrm{m}
\end{aligned}
$$

(d)

FIGURE 19: Responses at the analysis node of GG rotor with influence of bending stiffness of SSS: (a) $\omega_{1}$; (b) $\omega_{2}$; (c) $\omega_{1}-\omega_{2}$; (d) $\omega_{1}+\omega_{2}$.

TABLE 10: Radius clearance of SFD 4.

\begin{tabular}{lccccc}
\hline Model & $\begin{array}{c}1 \\
(1 \% \mathrm{o})\end{array}$ & $\begin{array}{c}2 \\
(1.5 \% \mathrm{o})\end{array}$ & $\begin{array}{c}3 \\
(2 \% \mathrm{o})\end{array}$ & $\begin{array}{c}4 \\
(2.5 \% \mathrm{o})\end{array}$ & $\begin{array}{c}5 \\
(3 \% \mathrm{o})\end{array}$ \\
\hline $\begin{array}{l}\text { Radius clearance } \\
(\mathrm{mm})\end{array}$ & 0.031 & 0.046 & 0.061 & 0.076 & 0.092 \\
\hline
\end{tabular}

Figures 16 and 17 show the responses of the SSS rotorbearing system at the analysis nodes of the PT and GG rotors, respectively, for different values of the SSS radial stiffness. Figures 16 and 17 show that with increasing SSS radial stiffness, the responses of $\omega_{1}, \omega_{1}-\omega_{2}$, and $\omega_{1}+\omega_{2}$ at the analysis nodes of both rotors all increase initially and then decrease. Figures 16(b) and 17(b) show that when the SSS radial stiffness is less than $1 \times 10^{7} \mathrm{~N} / \mathrm{m}$, the vibration response of the GG rotor can hardly be observed at the analysis nodes of both rotors.

Combining the information in Figures 16 and 17 shows that for a rotor-bearing system with an SSS, the probability of coupling vibration arising is reduced by avoiding certain specific values of the radial stiffness. Taking the present model as an example, from the perspective of reducing the coupling vibration response, the SSS radial stiffness should not be close to $5 \times 10^{7} \mathrm{~N} / \mathrm{m}$.

4.3. Influence of Bending Stiffness of Shared Support Structure. The bending stiffness of the SSS is given in Table 9, and the bending stiffness value range of SSS refers to the maximum and minimum stiffness allowed in the design stage of the tester. And the other calculation parameters of the dynamic model are consistent with those of the model in Section 3.3. Figures 18 and 19 show the responses of the SSS rotor-bearing system at the analysis nodes of the PT and GG rotors, respectively, for different values of the SSS bending stiffness.

Figures 18 and 19 show that when the SSS bending stiffness exceeds $1 \times 10^{6} \mathrm{~N} \cdot \mathrm{m} / \mathrm{rad}$, the curves almost overlap, and the responses of frequencies $\omega_{2}, \omega_{1}-\omega_{2}$, and $\omega_{1}+\omega_{2}$ are small at the analysis nodes of both the PT and GG rotors. Also, when the SSS bending stiffness is low, the responses of $\omega_{1}$ and $\omega_{2}$ have additional peaks in the low-frequency 


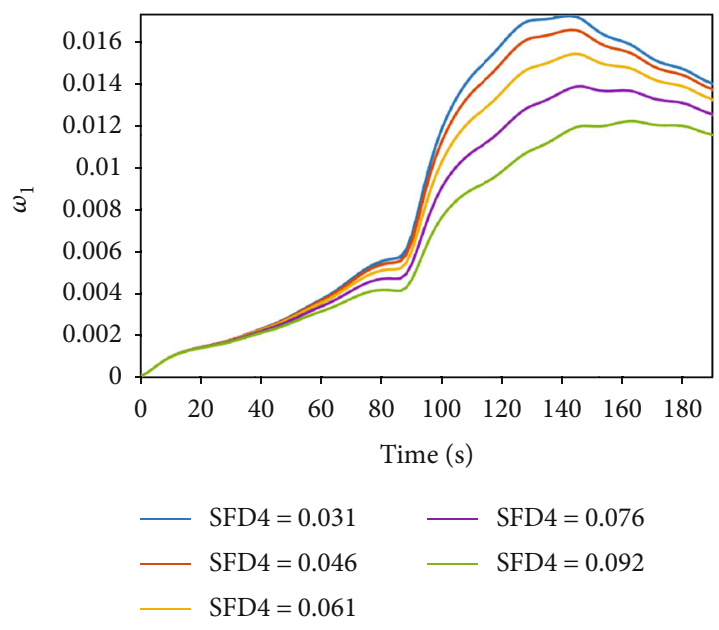

(a)

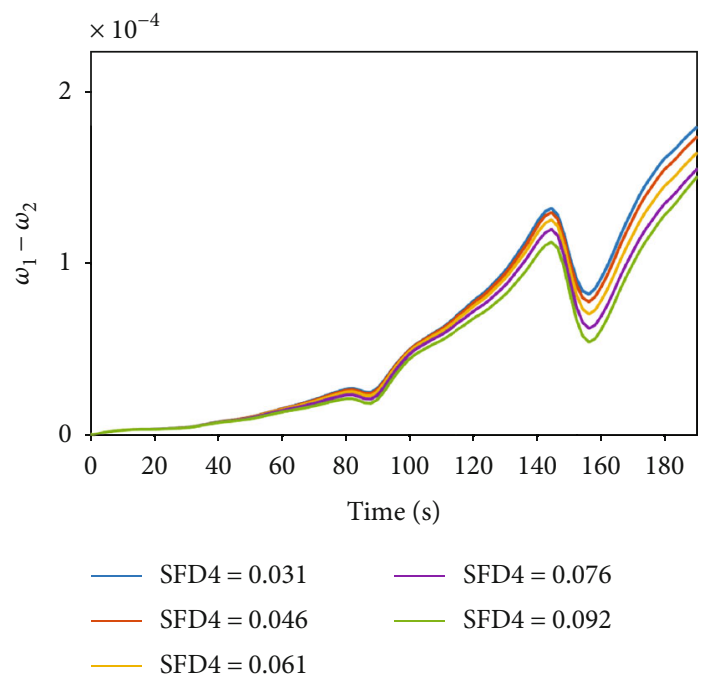

(c)

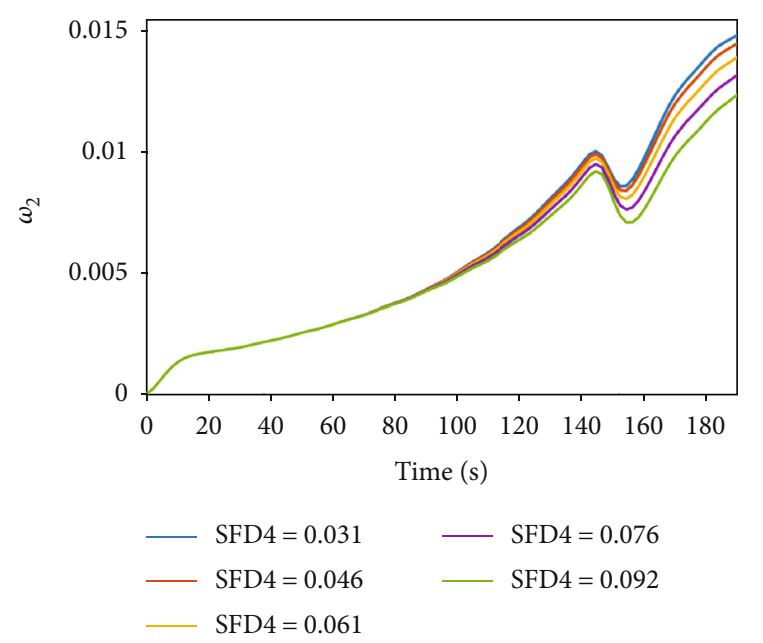

(b)

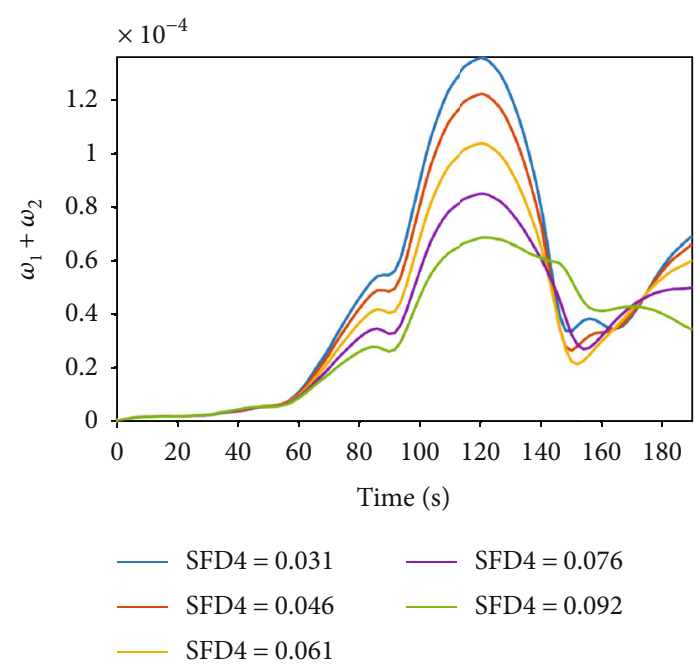

(d)

FIGURE 20: Responses at the analysis node of PT rotor with influence of radius clearance of SFD 4: (a) $\omega_{1}$; (b) $\omega_{2}$; (c) $\omega_{1}-\omega_{2}$; (d) $\omega_{1}+\omega_{2}$.

range; it means another critical speed due to the low bending stiffness of the SSS appeared. In this situation, the SSS and $\mathrm{PT}$ rotor are moving in phase, the relative shaft motion in the SFD has reduced motion, and hence, its ability to provide damping is greatly reduced. Thus, a high amplitude of motion is obtained in the low-frequency range which is shown in Figure 19(b).

For the present SSS rotor-bearing system, when the SSS bending stiffness exceeds $1 \times 10^{6} \mathrm{~N} \cdot \mathrm{m} / \mathrm{rad}$, the response of the rotor-bearing system no longer changes with changes in the SSS bending stiffness. Therefore, optimizing the SSS to have greater bending stiffness would help to suppress the low-frequency coupling vibration response of the rotor-bearing system and reduce the $\omega_{2}$ response.

4.4. Influence of Radius Clearance of SFD 4. The radius clearance of SFD 4 is given in Table 10 and corresponds to $1-3 \%$ of the journal radius. The other calculation parameters of the dynamic model are consistent with those of the model in
Section 3.3. Figures 20 and 21 show the response of the SSS rotor-bearing system at the analysis nodes of the PT and GG rotors, respectively, for different values of the radius clearance of SFD 4.

Figures 20(a)-20(c) show that the responses of $\omega_{1}, \omega_{2}$, and $\omega_{1}-\omega_{2}$ at the analysis node of the PT rotor all decrease with increasing radius clearance of SFD 4 . Before $140 \mathrm{~Hz}$, the response of $\omega_{1}+\omega_{2}$ at the analysis node of the PT rotor decreases with increasing radius clearance, and the peak response decreases by more than $50 \%$. After $140 \mathrm{~Hz}$, the response of $\omega_{1}+\omega_{2}$ for each radius gap is at a low level. Figures 21(b) and 21(d) show that the responses of $\omega_{2}$ and $\omega_{1}+\omega_{2}$ at the analysis node of the GG rotor decrease with increasing radius clearance of SFD 4 . The response of $\omega_{1}-$ $\omega_{2}$ at the analysis node of the GG rotor decreases with increasing radius clearance before $140 \mathrm{~Hz}$; after $140 \mathrm{~Hz}$, the response of $\omega_{1}-\omega_{2}$ does not change regularly with the radius clearance of SFD 4, but in general, the peak response for large radius clearance is smaller than that for small 


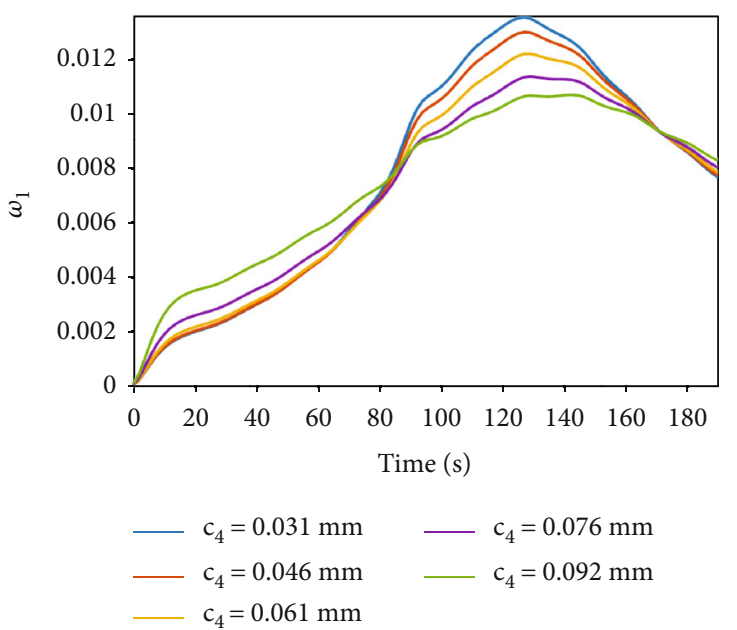

(a)

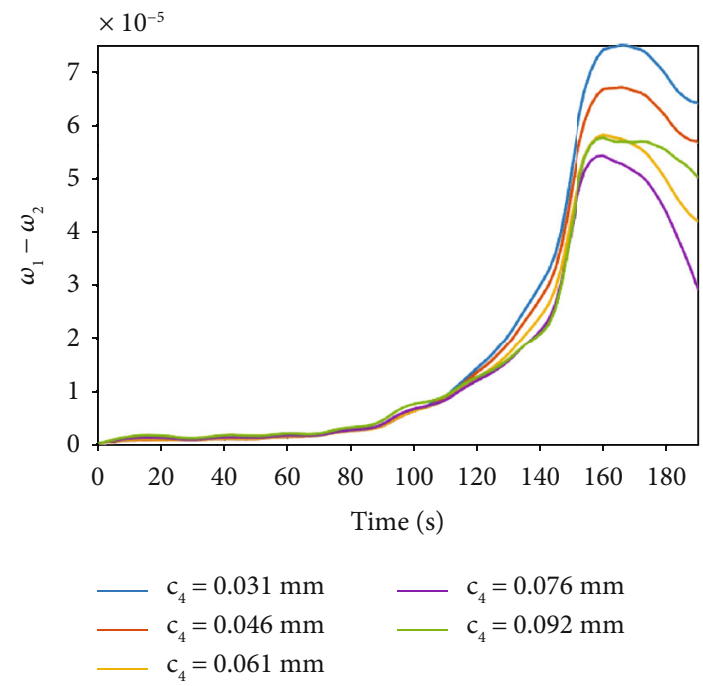

(c)
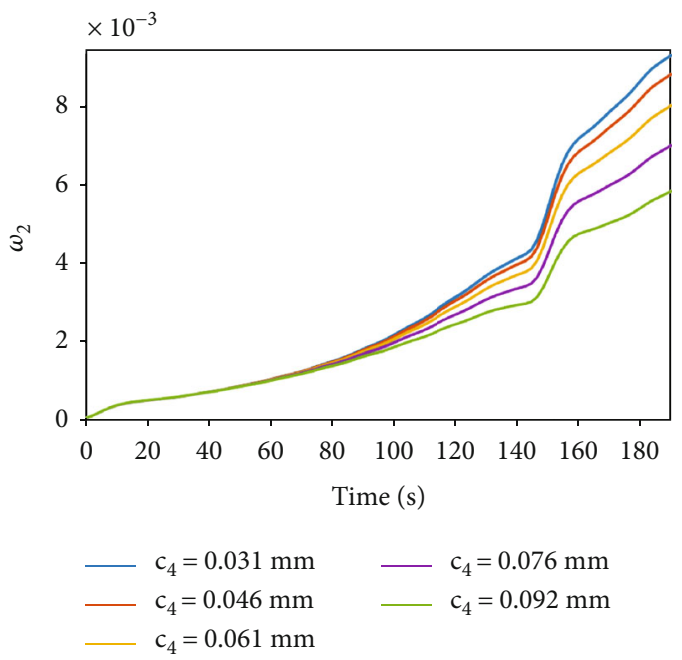

(b)

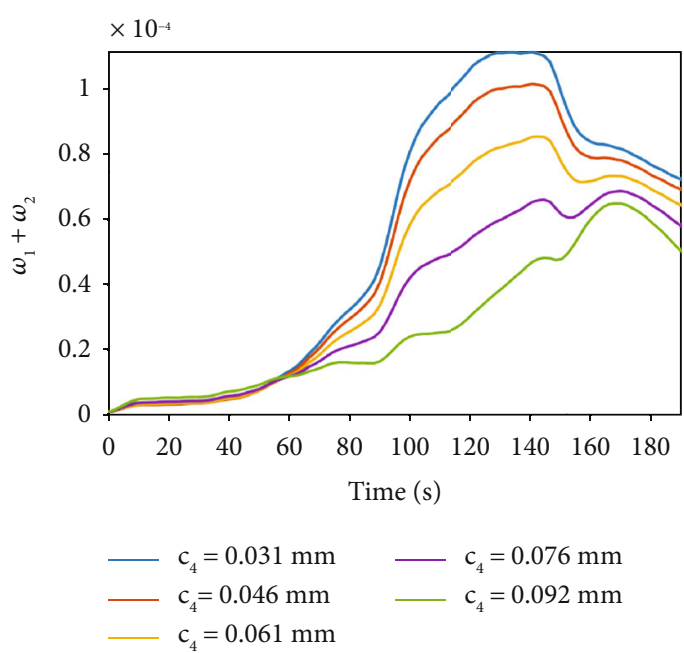

(d)

FIGURE 21: Responses at the analysis node of GG rotor with influence of radius clearance of SFD 4: (a) $\omega_{1}$; (b) $\omega_{2}$; (c) $\omega_{1}-\omega_{2}$; (d) $\omega_{1}+\omega_{2}$.

radius clearance. As radius clearance of SFD 4 increases, the response of $\omega_{1}$ at the analysis node of the GG rotor increases before $90 \mathrm{~Hz}$ and then reduces after $90 \mathrm{~Hz}$, but judging from the response amplitude, the response amplitude for large oilfilm thickness has a smaller range of change and the maximum amplitude in the full frequency range is smaller than the response amplitude for small radius clearance of SFD 4.

Therefore, increasing the oil-film clearance of SFD 4 within a reasonable range would help to (i) suppress the coupling vibration response of the SSS rotor-bearing system and (ii) reduce the responses corresponding to the fundamental frequencies of the PT and GG rotors.

4.5. Influence of Radius Clearance of SFD 6. The radius clearance of SFD 6 is given in Table 11 and corresponds to $1-3 \%$ of the journal radius. The other calculation parameters of the dynamic model are consistent with those of the model in Section 3.3. Figures 22 and 23 show the responses of the
TABLE 11: Radius clearance of SFD 6.

\begin{tabular}{lccccc}
\hline Model & $\begin{array}{c}1 \\
(1 \% \mathrm{o})\end{array}$ & $\begin{array}{c}2 \\
(1.5 \% \mathrm{o})\end{array}$ & $\begin{array}{c}3 \\
(2 \% \mathrm{o})\end{array}$ & $\begin{array}{c}4 \\
(2.5 \% \mathrm{o})\end{array}$ & $\begin{array}{c}5 \\
(3 \% \mathrm{o})\end{array}$ \\
\hline $\begin{array}{l}\text { Radius clearance } \\
(\mathrm{mm})\end{array}$ & 0.027 & 0.040 & 0.061 & 0.053 & 0.080 \\
\hline
\end{tabular}

SSS rotor-bearing system for different values of the radius clearance of SFD 6.

Comparing the response amplitudes of each frequency in Figures 22 and 23 shows that the oil-film thickness of SFD 6 has a greater impact on the response amplitudes of frequencies $\omega_{1}$ and $\omega_{1}-\omega_{2}$ at the analysis nodes of both the PT and GG rotors but little influence on those of $\omega_{2}$ and $\omega_{1}+\omega_{2}$. From the perspective of suppressing the maximum amplitude, a reasonable increase in the oil-film clearance of SFD 6 would help to reduce the response amplitudes of $\omega_{1}$ and 


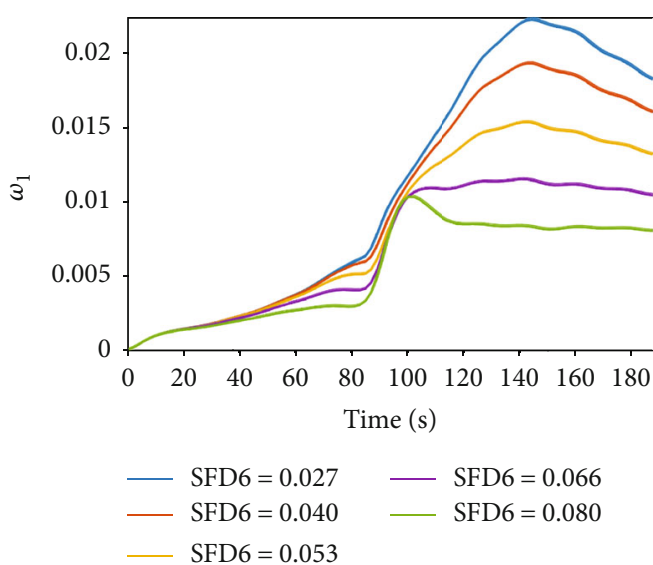

(a)

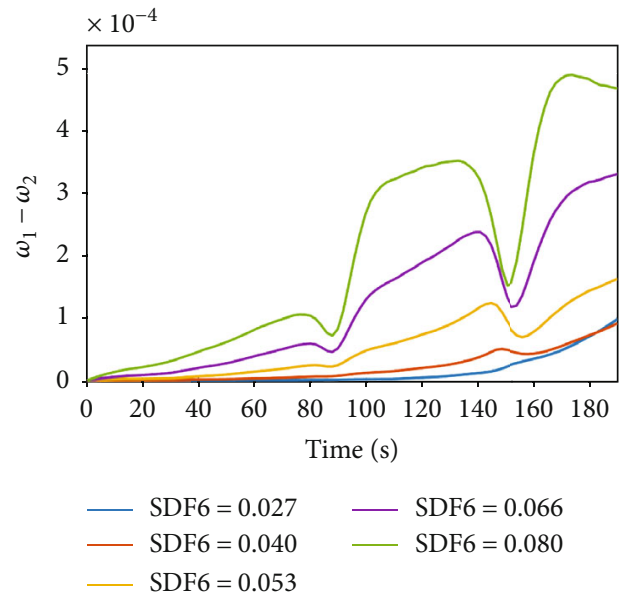

(c)

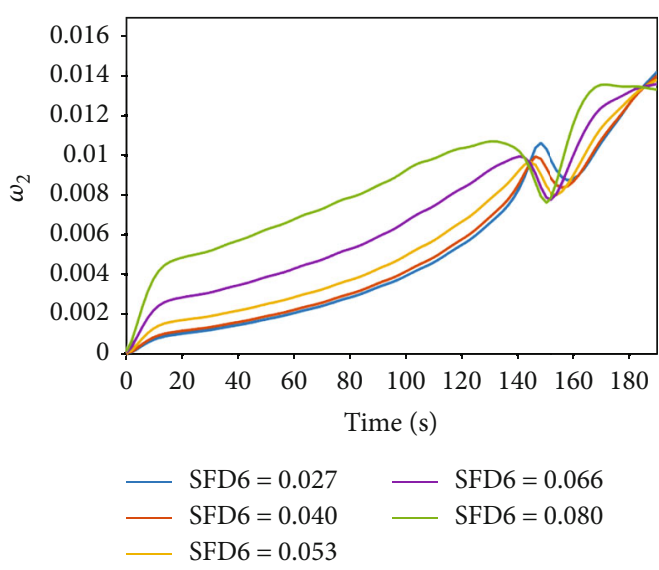

(b)

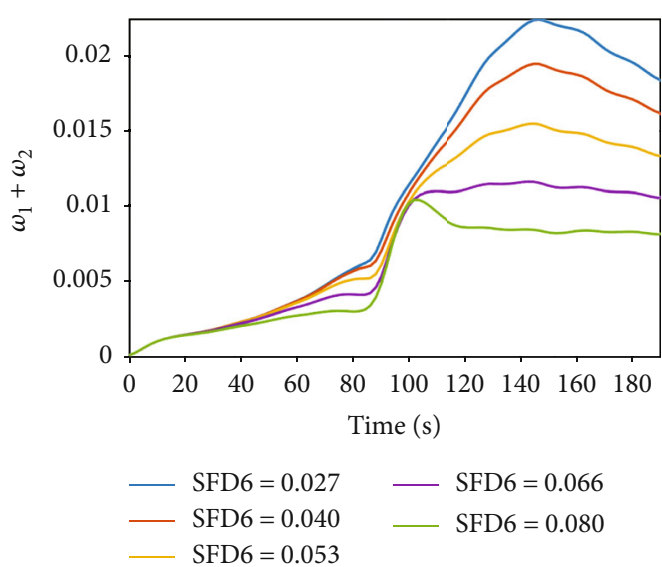

(d)

Figure 22: Responses at the analysis node of PT rotor with influence of radius clearance of SFD 6: (a) $\omega_{1}$; (b) $\omega_{2}$; (c) $\omega_{1}-\omega_{2}$; (d) $\omega_{1}+\omega_{2}$.

$\omega_{1}-\omega_{2}$ at the analysis nodes of the PT and GG rotors of the SSS rotor-bearing system.

\section{Conclusions}

Based on the features of a turboshaft engine with a turbine SSS, a test system with a turbine SSS was designed, and an FE model of the test system was established. We studied how the unbalance of the PT rotor, the radial and bending stiffnesses of the SSS, and the radius clearances of the SFDs at the SSS affected the coupling vibration response of the rotor-bearing system, and the main conclusions are as follows:

(1) In this paper, the experiment and simulation analysis of the SSS rotor-bearing system with SFDs have been carried out for the first time; the reliability of the modeling method in this article is verified through experiments and comparison with ANSYS. Both the experimental and theoretical research under nonlinear conditions showed that an SSS rotor-bearing system with SFDs may exhibit coupling vibration responses with frequencies $\omega_{1}-\omega_{2}$ and $\omega_{1}+\omega_{2}$
(2) The spool unbalance of the PT rotor has a greater impact on the coupling vibration response of a rotor-bearing system with an SSS. Since the disk on the PT rotor is close to the SSS, the unbalanced force on the disk is almost completely transferred to the SSS through the No. 5 and No. 6 bearings. Exerting strict control over the spool unbalance would help to suppress the amplitude of fundamental frequency $\left(\omega_{2}\right)$ and combined frequency $\left(\omega_{1}-\omega_{2}\right.$ and $\left.\omega_{1}+\omega_{2}\right)$

(3) The SSS radial stiffness $\left(k_{x x}\right)$ should avoid certain specific frequency components to reduce the probability of coupling vibration arising in an SSS rotorbearing system. Because the radial stiffness of the SSS structure directly affects the radial stiffness of the support near the turbine, the change of the radial stiffness of SSS may directly lead to the change of the critical speed of the rotor system, which leads to the change of the response of the rotor system. Furthermore, the bending stiffness of the SSS also indirectly affects the radial stiffness of the support of the rotor system close to the turbine. When the bending stiffness of SSS is small, it will indirectly weaken the radial stiffness of the support of the rotor system 


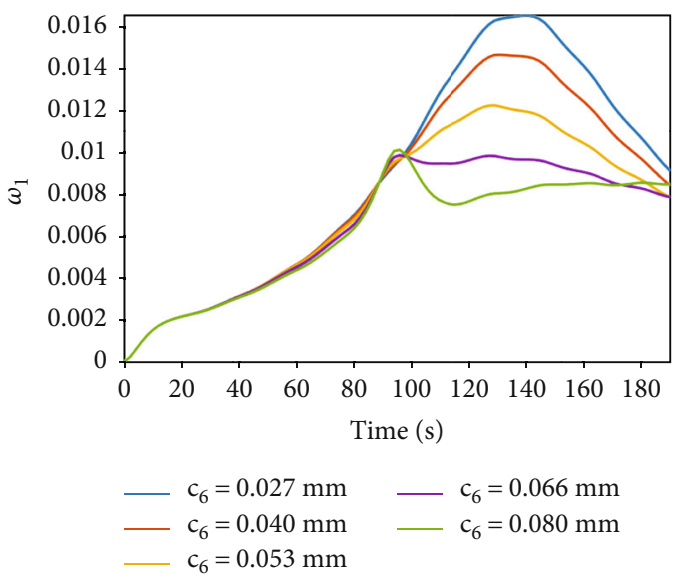

(a)

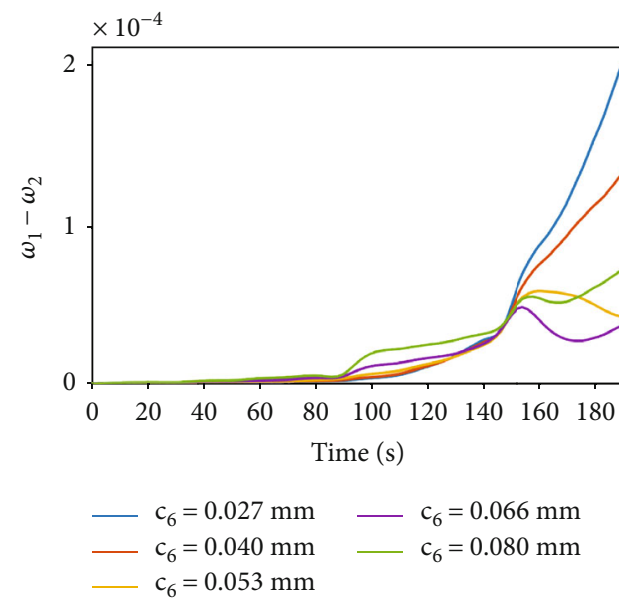

(c)

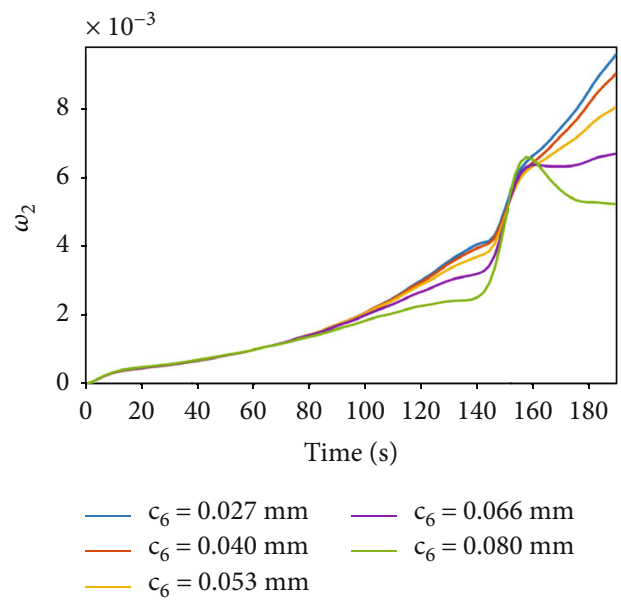

(b)

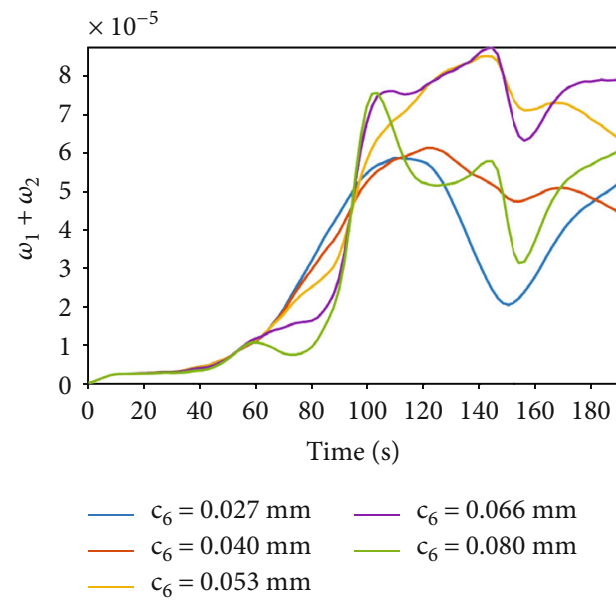

(d)

FIGURE 23: Responses at the analysis node of GG rotor with influence of radius clearance of SFD 6: (a) $\omega_{1}$; (b) $\omega_{2}$; (c) $\omega_{1}-\omega_{2}$; (d) $\omega_{1}+\omega_{2}$.

close to the turbine. Therefore, a larger SSS bending stiffness $\left(k_{x z}\right)$ has a positive impact on suppressing the coupling vibration response of a rotor-bearing system with an SSS

(4) What is more, in a reasonable range, increasing the radial clearances of the SFDs at the SSS would help to reduce the response amplitude of a rotor-bearing system with an SSS. In the traditional structural design, the stiffness of the connection between the SFDs and the engine casing is relatively large; the housing of the SFDs will not move. In the SSS structure, the possible displacement of the SSS structure may cause the effective oil film thickness of the SFD to be less than the design thickness. Therefore, an appropriate increase in the oil film thickness within a reasonable range is beneficial to suppress the amplitude of combined frequency $\left(\omega_{1}-\omega_{2}\right.$ and $\left.\omega_{1}+\omega_{2}\right)$

In future work, the influence of SSS structural parameter changes on the nonlinear response of the rotor system will be verified by further experiments, the influence of SSS's other structural parameter changes on the nonlinear response of the rotor system will be evaluated.

\section{Data Availability}

Please contact the corresponding author.

\section{Disclosure}

A preprint [37] has previously been published in https:// www.researchsquare.com/article/rs-157225/v1.

\section{Conflicts of Interest}

The authors declare that they have no known competing financial interests or personal relationships that could have appeared to influence the work reported in this paper.

\section{Authors' Contributions}

Jiaqi Han performed conceptualization, methodology, software, validation, and writing, reviewing, and editing. Guihuo Luo and Wei Chen performed project administration and 
reviewing. Fei Wang contributed to the software, validation, and resources. Lulu Liu performed reviewing and polishing. Zhenhua Zhao and Gang Luo performed visualization and investigation.

\section{Acknowledgments}

This work was supported by the National Natural Science Foundation of China (Grant Ref. 51775266) and the National Major Science and Technology Projects of China (Grant Ref. 2017-IV-0006-0043).

\section{References}

[1] J. F. Seda, "Aircraft engine with inter-turbine engine frame," 2005, US Patent US6708482.

[2] K. B. Kumar, N. Somanath, and W. A. Sowa, "Mid-turbine frame," 2012, US Patent US8181466.

[3] K. Lu, Y. Chen, Q. Cao, L. Hou, and Y. Jin, "Bifurcation analysis of reduced rotor model based on nonlinear transient POD method," International Journal of Non-Linear Mechanics, vol. 89, pp. 83-92, 2017.

[4] K. Lu, Y. Yang, Y. Xia, and C. Fu, "Statistical moment analysis of nonlinear rotor system with multi uncertain variables," Mechanical Systems and Signal Processing, vol. 116, pp. 1029-1041, 2018.

[5] F. Thiery and J. O. Aidanpäaä, "Nonlinear vibrations of a misaligned bladed Jeffcott rotor," Nonlinear Dynamics, vol. 86, no. 3, pp. 1807-1821, 2016.

[6] R. Yang, Y. Jin, L. Hou, and Y. Chen, "Study for ball bearing outer race characteristic defect frequency based on nonlinear dynamics analysis," Nonlinear Dynamics, vol. 90, no. 2, pp. 781-796, 2017.

[7] P. Gao, L. Hou, R. Yang, and Y. Chen, "Local defect modelling and nonlinear dynamic analysis for the inter-shaft bearing in a dual-rotor system," Applied Mathematical Modelling, vol. 68, pp. 29-47, 2019.

[8] P. Gao, Y. Chen, and L. Hou, "Nonlinear thermal behaviors of the inter-shaft bearing in a dual-rotor system subjected to the dynamic load," Nonlinear Dynamics, vol. 101, no. 1, pp. 191209, 2020.

[9] L. Hou, Y. Chen, Y. Fu, H. Chen, Z. Lu, and Z. Liu, “Application of the HB-AFT method to the primary resonance analysis of a dual-rotor system," Nonlinear Dynamics, vol. 88, no. 4, pp. 2531-2551, 2017.

[10] K. Lu, Y. Jin, P. Huang et al., "The applications of POD method in dual rotor-bearing systems with coupling misalignment," Mechanical Systems and Signal Processing, vol. 150, p. 107236, 2021.

[11] N. Wang, C. Liu, D. Jiang, and K. Behdinan, "Casing vibration response prediction of dual-rotor-blade-casing system with blade-casing rubbing," Mechanical Systems and Signal Processing, vol. 118, pp. 61-77, 2019.

[12] G. Chen, "Simulation of casing vibration resulting from bladecasing rubbing and its verifications," Journal of Sound and Vibration, vol. 361, pp. 190-209, 2016.

[13] P. Yu, D. Zhang, Y. Ma, and J. Hong, "Dynamic modeling and vibration characteristics analysis of the aero-engine dual-rotor system with fan blade out," Mechanical Systems and Signal Processing, vol. 106, pp. 158-175, 2018.
[14] Y. Yang, H. Ouyang, Y. Yang, D. Cao, and K. Wang, "Vibration analysis of a dual-rotor-bearing-double casing system with pedestal looseness and multi-stage turbine blade-casing rub," Mechanical Systems and Signal Processing, vol. 143, p. $106845,2020$.

[15] H. D. Nelson and J. M. McVaugh, "The dynamics of rotorbearing systems using finite elements," Journal of Engineering for Industry, vol. 98, no. 2, pp. 593-600, 1976.

[16] H. D. Nelson, "A finite rotating shaft element using Timoshenko beam theory," Journal of Mechanical Design - the ASME, vol. 102, no. 4, pp. 793-803, 1980.

[17] D. A. Glasgow and H. D. Nelson, "Stability analysis of rotorbearing systems using component mode synthesis," Journal of Mechanical Design - the ASME, vol. 102, no. 2, pp. 352359, 1980.

[18] H. D. Nelson, W. L. Meacham, D. P. Fleming, and A. F. Kascak, "Nonlinear analysis of rotor-bearing systems using component mode synthesis," Journal of Engineering for Power, vol. 105, pp. 606-614, 1983.

[19] H. D. Chiang, C. Hsu, W. Jeng, S. Tu, and W. Li, "Turbomachinery dual rotor-bearing system analysis," ASME Turbo Expo: Power for Land, Sea, and Air, vol. 36096, pp. 803-810, 2002.

[20] H. D. Chiang, C. Hsu, and S. Tu, "Rotor-bearing analysis for turbomachinery single-and dual-rotor systems," Journal of Propulsion and Power, vol. 20, no. 6, pp. 1096-1104, 2004.

[21] F. Wang, G. Luo, X. Yang, and H. Cui, "Research on modeling and dynamic characteristics of complex coaxial rotor system," Journal of Vibroengineering, vol. 19, no. 3, pp. 1524-1545, 2017.

[22] L. Della Pietra and G. Adiletta, "The squeeze film damper over four decades of investigations. Part I: characteristics and operating features," Shock Vib. Digest., vol. 34, pp. 3-26, 2002.

[23] G. Adiletta and L. Della Pietra, "The squeeze film damper over four decades of investigations. Part II: rotordynamic analyses with rigid and flexible rotors," Shock Vib. Digest., vol. 34, pp. 97-126, 2002.

[24] H. R. Heidari and P. Safarpour, "Design and modeling of a novel active squeeze film damper," Mechanism and Machine Theory, vol. 105, pp. 235-243, 2016.

[25] K. H. Groves and P. Bonello, "Improved identification of squeeze-film damper models for aeroengine vibration analysis," Tribology International, vol. 43, no. 9, pp. 1639-1649, 2010.

[26] M. A. Rezvani and E. J. Hahn, "Floating ring squeeze film damper: theoretical analysis," Tribology International, vol. 33, no. 3-4, pp. 249-258, 2000.

[27] L. San Andres, "Force coefficients for a large clearance open ends squeeze film damper with a central feed groove: experiments and predictions," Tribology International, vol. 71, pp. 17-25, 2014.

[28] B. Han and Q. Ding, "Forced responses analysis of a rotor system with squeeze film damper during flight maneuvers using finite element method," Mechanism and Machine Theory, vol. 122, pp. 233-251, 2018.

[29] J. I. Inayat-Hussain, H. Kanki, and N. W. Mureithi, "Chaos in the unbalance response of a rigid rotor in cavitated squeezefilm dampers without centering springs," Chaos, Solitons and Fractals, vol. 13, no. 4, pp. 929-945, 2002.

[30] W. Qin, J. Zhang, and X. Ren, "Response and bifurcation of rotor with squeeze film damper on elastic support," Chaos, Solitons and Fractals, vol. 39, no. 1, pp. 188-195, 2009. 
[31] H. Chen, L. Hou, and Y. Chen, "Bifurcation analysis of a rigidrotor squeeze film damper system with unsymmetrical stiffness supports," Archive of Applied Mechanics, vol. 87, no. 8, pp. 1347-1364, 2017.

[32] Z. Luo, J. Wang, R. Tang, and D. Wang, "Research on vibration performance of the nonlinear combined support-flexible rotor system," Nonlinear Dynamics, vol. 98, no. 1, pp. 113-128, 2019.

[33] W. J. Gooding, M. A. Meier, and E. J. Gunter, "Nonlinear response and stability of an experimental overhung compressor mounted with a squeeze film damper," ASME Turbo Expo, 2020.

[34] M. A. Xinxing, M. A. Hui, H. QIN, X. GUO, C. ZHAO, and Y. U. Mingyue, "Nonlinear vibration response characteristics of a dual-rotor-bearing system with squeeze film damper," Chinese Journal of Aeronautics, vol. 34, pp. 128-147, 2021.

[35] J. I. Inayat-Hussain, "Bifurcations in the response of a flexible rotor in squeeze-film dampers with retainer springs," Chaos, Solitons and Fractals, vol. 39, no. 2, pp. 519-532, 2009.

[36] H. L. Zhou, G. H. Luo, G. Chen, and F. Wang, "Analysis of the nonlinear dynamic response of a rotor supported on ball bearings with floating-ring squeeze film dampers," Mechanism and Machine Theory, vol. 59, pp. 65-77, 2013.

[37] J. Han, G. Luo, and F. Wang, "Coupling vibration analysis of turbine shared support rotor-bearing system with squeeze film dampers," 2021, https://www.researchsquare.com/article/rs157225/v1. 